\title{
Delayed Satiety-Like Actions and Altered Feeding Microstructure by a Selective Type 2 Corticotropin-Releasing Factor Agonist in Rats: Intra-Hypothalamic Urocortin 3 Administration Reduces Food Intake by Prolonging the Post-Meal Interval
}

\author{
Éva M Fekete ${ }^{1,2}$, Koki Inoue ${ }^{3}$, Yu Zhao', Jean E Rivier ${ }^{4}$, Wylie W Vale ${ }^{4}$, Attila Szücs ${ }^{5}$, George F Koob' \\ and Eric P Zorrilla*, ${ }^{*, 6}$
}

\begin{abstract}
'Molecular and Integrative Neurosciences Department, The Scripps Research Institute, La Jolla, CA, USA; ${ }^{2}$ Department of Endocrine Neurobiology, Institute of Experimental Medicine, Hungarian Academy of Sciences, Budapest, Hungary; ${ }^{3}$ Department of Neuropsychiatry, Osaka City University Medical School, Abeno-ku, Osaka-city, Osaka, Japan; ${ }^{4}$ Clayton Foundation Laboratory for Peptide Biology, The Salk Institute, La Jolla, CA, USA; ${ }^{5}$ Institute for Nonlinear Science, University of Califormia San Diego, La Jolla, CA, USA; ${ }^{6}$ Harold L Dorris Neurological Research Institute, The Scripps Research Institute, La Jolla, CA, USA
\end{abstract}

\begin{abstract}
Brain corticotropin-releasing factor/urocortin (CRF/Ucn) systems are hypothesized to control feeding, with central administration of 'type 2' urocortins producing delayed anorexia. The present study sought to identify the receptor subtype, brain site, and behavioral mode of action through which Ucn 3 reduces nocturnal food intake in rats. Non-food-deprived male Wistar rats $(n=176)$ were administered Ucn 3 into the lateral (LV) or fourth ventricle, or into the ventromedial or paraventricular nuclei of the hypothalamus (VMN, PVN) or the medial amygdala (MeA), regions in which Ucn 3 is expressed in proximity to $\mathrm{CRF}_{2}$ receptors. LV Ucn 3 suppressed ingestion during the third-fourth post-injection hours. LV Ucn 3 anorexia was reversed by cotreatment with astressin 2 - $\mathrm{B}$, a selective $\mathrm{CRF}_{2}$ antagonist and not observed following equimole subcutaneous or fourth ventricle administration. Bilateral intra-VMN and intra-PVN infusion, more potently than LV infusion, reduced the quantity (57-73\%) and duration of ingestion (32-68\%) during the third-fourth post-infusion hours. LV, intra-PVN and intra-VMN infusion of Ucn 3 slowed the eating rate and reduced intake by prolonging the post-meal interval. Intra-VMN Ucn 3 reduced feeding bout size, and intra-PVN Ucn 3 reduced the regularity of eating from pellet to pellet. Ucn 3 effects were behaviorally specific, because minimal effective anorectic $U c n 3$ doses did not alter drinking rate or promote a conditioned taste aversion, and site-specific, because intra-MeA Ucn 3 produced a nibbling pattern of more, but smaller meals without altering total intake. The results implicate the VMN and PVN of the hypothalamus as sites for Ucn 3-CRF 2 control of food intake.

Neuropsychopharmacology (2007) 32, 1052-1068. doi: I0. I038/sj.npp. I 30 I2I4; published online 4 October 2006
\end{abstract}

Keywords: urocortin I or urocortin 3; corticotropin-releasing factor or corticotropin-releasing hormone; ventromedial hypothalamic nucleus or paraventricular nucleus of the hypothalamus; medial amygdala; meal pattern or microstructure; food intake or feeding

\section{INTRODUCTION}

Central infusion of corticotropin-releasing factor (CRF) family peptides (CRF and urocortins (Ucn)) alters energy homeostasis through two G-protein-coupled receptors

*Correspondence: Dr EP Zorrilla, Molecular and Integrative Neurosciences Department, The Scripps Research Institute, SP30-2400, 10550 North Torrey Pines Road, La Jolla, CA 92037, USA, Tel: + I 858784 74|6, Fax: + I 858784 7405, E-mail: ezorrilla@scripps.edu Received I December 2005; revised 25 July 2006; accepted 24 August 2006

Online publication: 5 September 2006 at http://www.acnp.org/ citations/Npp090506050707/default.pdf
$\left(\mathrm{CRF}_{1}\right.$ and $\left.\mathrm{CRF}_{2}\right)$. Ucn 1 has greater $\mathrm{CRF}_{2}$ affinity and more potently suppresses feeding than CRF, which led to the hypothesis that brain $\mathrm{CRF}_{2}$ activation reduces food intake (Spina et al, 1996). Accordingly, $\mathrm{CRF}_{2}$ deficiency, $\mathrm{CRF}_{2}$ antisense, and $\mathrm{CRF}_{2}$ antagonists attenuated intracerebroventricular (i.c.v.) $\mathrm{CRF} / \mathrm{Ucn}$ 1-induced anorexia in rodents. However, Ucn 1 and CRF also have high $\mathrm{CRF}_{1}$ affinity, through which they acutely reduce feeding, so whether $\mathrm{CRF}_{2}$ activation was sufficient to reduce ingestion remained unclear (see Zorrilla et al, 2003).

Separate genes encoding preproteins that contain $\mathrm{CRF}_{2}$ agonists were then discovered, and putative mature peptides were proposed-Ucn 2 and Ucn 3 (N-terminally 
shortened sequences of stresscopin-related peptide and stresscopin, respectively) (Hsu and Hsueh, 2001; Lewis et al, 2001; Reyes et al, 2001). Like Ucn 1, but unlike CRF, Ucn 2 and $U c n 3$ have high $\mathrm{CRF}_{2}$ affinity. However, unlike Ucn 1, the type 2 urocortins ( $U c n$ 2, $U c n$ ) are selective $\mathrm{CRF}_{2}$ agonists. Ucn 2 is $\sim 1000$-fold more $\mathrm{CRF}_{2}$-selective than Ucn 1, and Ucn 3 does not activate $\mathrm{CRF}_{1}$ receptors (Lewis et al, 2001; Reyes et al, 2001; Hoare et al, 2005). Ucn 3 is unique in that it does not bind to the rat CRF-binding protein (Jahn et al, 2004), a secreted glycoprotein hypothesized to limit (Behan et al, 1995) or to allow (Ungless et al, 2003) CRF receptor agonist effects by complexing with ligand. Thus, Ucn 3 is a specific, direct $\mathrm{CRF}_{2}$ receptor agonist.

Initial studies using type 2 urocortins suggest that $\mathrm{CRF}_{2}$ activation is sufficient to reduce feeding. We and others found that i.c.v. Ucn 2 reduced nocturnal food intake (Zorrilla et al, 2004), beginning 3-6h postinjection in nondeprived rats (Inoue et al, 2003; Ohata and Shibasaki, 2004; de Groote et al, 2005) or mice (Reyes et al, 2001). Ucn 3 (i.c.v.) also reduced food intake with delayed onset in nondeprived rats (Ohata and Shibasaki, 2004; de Groote et al, 2005). Although acute-onset anorectic effects of Ucn 2 or Ucn 3 were observed in food-deprived mice (Pelleymounter et al, 2004), such effects were not seen in food-deprived rats (Ohata and Shibasaki, 2004). Thus, i.c.v. type 2 urocortins produce delayed-onset anorexia in rats.

The brain sites through which $U \mathrm{cn} 3$ reduces ingestion are unknown. In rodents, Ucn 3's putative receptor, $\mathrm{CRF}_{2(\mathrm{a})}$, is localized in regions that control feeding, including the ventromedial and paraventricular hypothalamic nuclei (VMN, PVN), nucleus tractus solitarius (NTS), medial and posterior cortical amygdala (MeA, CoA), and lateral septum (LS) (Van Pett et al, 2000). To evaluate candidate sites of Ucn $3-\mathrm{CRF}_{2}$ anorectic signaling, the present studies infused Ucn 3 into the LV (forebrain) and fourth (hindbrain) ventricle and into feeding-regulatory regions in which $U c n 3$ mRNA expression or $U c n 3$ terminals ( $\mathrm{Li}$ et al, 2002) occur in proximity to $\mathrm{CRF}_{2}$ expression. The behavioral mechanism of Ucn 3 anorexia was explored through microstructure analyses (Zorrilla et al, 2005a) and conditioned taste aversion (CTA) procedures.

\section{MATERIALS AND METHODS}

\section{Subjects}

The subjects were adult (225-250 g on arrival), male Wistar rats ( $n=176$; Charles River, Hollister, CA). On arrival, subjects were group housed in a $12 \mathrm{~h}$ dark/light cycle (dark phase beginning at $0800 \mathrm{~h}$ ), humidity (60\%)- and temperature-controlled vivarium. Standard rodent chow (LM-485 Diet 7012, Harlan Tekland, Madison, WI) and tap water were available ad libitum unless otherwise indicated. Subjects were acclimated to the vivarium for at least 1 week prior to the start of the experiments. Surgical and experimental procedures adhered to the National Institutes of Health Guide for the Care and Use of Laboratory Animals (NIH Publication number 85-23, revised 1996) and were approved by the Institutional
Animal Care and Use Committee of The Scripps Research Institute.

\section{Cannulation and Verification of Placement}

Anesthetized (isoflurane, 2-3\% in oxygen) subjects were secured in a stereotaxic frame (David Kopf Instruments, Tujunga, CA) and surgically implanted with intracranial cannulae using sterile technique. Rats that were to receive drug infusion into the LV were implanted with a stainless steel 22-gauge unilateral guide cannula (Plastics One Inc., Roanoke, VA) secured $1.2 \mathrm{~mm}$ above the target site (from bregma, AP: -0.6 and ML: \pm 2.0 ; V: -4.5 from the skull, with the interaural bar set at $+5.0 \mathrm{~mm}$ ) (Pellegrino et al, 1979). Rats that were to receive fourth ventricular infusions were implanted with a stainless steel 24-gauge guide cannula secured $2 \mathrm{~mm}$ above the target site (AP: average of $-11.6 \mathrm{~mm}$ from bregma and $+2.5 \mathrm{~mm}$ from the occipital crest, ML: $0.0 \mathrm{~mm}$ (midline), DV: $-4.5 \mathrm{~mm}$ from dura; Grill et al, 2002). Rats that were to receive intracerebral infusion received bilateral stainless steel 26-gauge guide cannulae secured $3 \mathrm{~mm}$ above the target site according to the following stereotaxic coordinates: final injection target sites for VMN (from bregma, AP: -2.8 and ML: \pm 0.4 , DV: -8.8 ), PVN (from bregma, AP: -1.8 and ML: \pm 0.4 , DV: -7.5 ), and the MeA (from bregma, AP: -3.4 and ML: \pm 3.3 , DV: -8.2 ). For fourth ventricle and intracerebral cannulation, the interaural bar was set at $-3.3 \mathrm{~mm}$ (Paxinos and Watson, 1998), and the dorsal-ventral coordinate was measured from dura. Patency was maintained by 28-, 31- and 33gauge stainless steel dummy stylets for LV, fourth ventricle, and intracerebral cannulae, respectively (Plastics One Inc.). Subjects were allowed a minimum of 7 days for postoperative recovery before the experiments, during which time they were frequently handled.

LV cannula placement was functionally confirmed by a positive dipsogenic response $(>5 \mathrm{ml}$ of water intake in nondeprived rats within $30 \mathrm{~min}$ of injection) to $\mathrm{LV}$ angiotensin II $(1 \mu \mathrm{g} / 5 \mu \mathrm{l})$ at the conclusion of studies. Of 82 rats that were subjects in studies that involved LV placements, seven were excluded for procedural reasons ( $n=5$ for nonresponding to angiotensin II, $n=2$ for loss or occlusion of cannulae). Placements of fourth ventricle and intra-parenchymal cannulae were confirmed histologically (Fekete et al, 2002). Cannulae and injector tracks were determined on the basis of existence of debris and mild glial proliferation. Of 50 rats with cannulae targeting the fourth ventricle, the injector end reached the fourth ventricle in 42 rats. In the remaining eight rats, the position of reconstructed cannulae was dorsal to the fourth ventricle, and those rats were removed from data analysis. Of 16 rats targeted for VMN placement, four were excluded for procedural reasons, which included loss or occlusion of cannulae $(n=2)$ or an inability to acquire or maintain stable baseline responding $(n=2)$. Of the 12 remaining rats, seven had injectors symmetrically located within the upper part of the target site ('hits'), and, in five rats, the position of the reconstructed cannula was outside the target site ('misses'). Of 17 rats targeted for PVN placement, five were excluded for procedural reasons ( $n=3$ for loss or occlusion of cannulae, $n=2$ for unstable baseline responding). Of the 12 remaining rats, eight were 'hits' and four were 'misses.' 
Of 11 rats targeted for MeA placement, three were excluded for procedural reasons ( $n=1$ for loss of cannula, $n=2$ for unstable baseline responding). Of the eight remaining rats, six were 'hits' and two were 'misses.' Primary data of interest were the results from rats with correct bilateral placements ('hits'). Data from incorrect placements are also reported separately to help interpret the site-specificity of effects.

\section{Drugs and Injections}

Murine Ucn 3, astressin ${ }_{2}-\mathrm{B}$ and angiotensin II were synthesized manually using solid-phase methodology, purified using high-pressure liquid chromatography and fully characterized using capillary zone electrophoresis, high-pressure liquid chromatography, and mass spectrometry, as described previously (Reyes et al, 2001; Rivier et al, 2002). Peptides were dissolved immediately before testing and kept on ice. The vehicle for treatments containing astressin ${ }_{2}-\mathrm{B}$ was sterile water, and $0.5 \times$ phosphate-buffered saline $(\mathrm{pH}=7.4)$ was used for other peptides.

Intraventricular infusion was performed through a $28-$ gauge (LV) or 31-gauge (fourth ventricle) injector that extended beyond the tip of the guide cannula (1.2 and $2 \mathrm{~mm}$ for LV and fourth ventricle, respectively). The injector was attached via polyethylene (PE-20) tubing to a $10-\mu l$ Hamilton microsyringe. Intraventricular treatments were injected ( 5 and $3 \mu \mathrm{l}$ for LV and fourth ventricle, respectively) over $1 \mathrm{~min}$. Intra-parenchymal treatments were infused $(0.5 \mu \mathrm{l} / \mathrm{side}$, simultaneously) over $1 \mathrm{~min}$ into the target site by automated syringe pumps (Harvard Apparatus. Holliston, MA, USA) via 33-gauge stainless steel injection needles connected to $10-\mu$ l Hamilton microsyringes by polyethylene tubing (PE-20). Injectors were left in place for $1 \mathrm{~min}$ after infusion to allow diffusion.

\section{Feeding Studies}

Free feeding. For free feeding experiments (Experiments 3 and 4), rats were habituated in individual test cages, identical in construction to their home cages, in a soundattenuated testing room from 0900 to $1500 \mathrm{~h}$ (during the dark cycle) after which they were returned to the vivarium. Tap water and rat chow were available ad libitum. On the test day, they were reacclimated to their individual test cages, which contained bedding from the previous day, for $2 \mathrm{~h}$. Injections then began at $1100 \mathrm{~h}$, and pre-measured lab chow and tap water were provided and measured at $2 \mathrm{~h}$ and $4 \mathrm{~h}$ after access.

Microstructure of ingestion. To study the microstructure of ingestion, rats were individually housed for $23 \mathrm{~h}$ each day in Plexiglas test cages $(22 \times 22 \times 35 \mathrm{~cm})$ equipped and validated for this purpose (Zorrilla et al, 2005a,b). Cages had a wire-mesh floor and were located in ventilated, soundattenuating enclosures equipped with a $1.1 \mathrm{~W}$ bulb that provided a 12:12 h reversed light-dark cycle with lights off at $1000 \mathrm{~h}$. Rats obtained individual palatable chow pellets ( $45 \mathrm{mg}$ precision food pellets, formula $\mathrm{A} / \mathrm{I}$; carbohydrate $60.0 \%$, fat $3.7 \%$, protein $24.1 \%$, ash $7.0 \%$, moisture $5.2 \%$, $370 \mathrm{Cal} / 100 \mathrm{~g}$; Research Diets In., Brunswick, NJ) from a trough replenished by an automated dispenser (Med Associates, St Albans, VT). The acquisition of individual pellets was detected by photobeams that were broken $(0.5 \mathrm{~s}$ duration) when the rat displaced a freely swinging door to access the pellet in the trough. An additional pellet was not delivered until the door returned to a neutral position and a $3.25 \mathrm{~s}$ timeout period had elapsed to prevent duplicate pellet deliveries (timeout based on ÉM Fekete and EP Zorrilla, unpublished observations of inter-pellet intervals), thereby allowing resolution of feeding at the unit of individual pellets. Water delivery $(0.1 \mathrm{ml})$ into a reservoir was governed by a response-contingent solenoid (WW Grainger, Lincolnshire, IL) that was activated by nosepoke interruption $(0.5 \mathrm{~s})$ of photobeams monitoring a separate hole, with a $1 \mathrm{~s}$ timeout period to prevent duplicate delivery. Responses were recorded automatically by an IBM PCcompatible microcomputer with $10 \mathrm{~ms}$ resolution. Spillage is low in this system $(1.2 \pm 0.2 \%$ of food responses; $n=105$ sessions) (Zorrilla et al, 2005a). Rats were removed from the apparatus daily for $60 \mathrm{~min} 1 \mathrm{~h}$ before the onset of the dark cycle to permit cage maintenance and experimental treatment.

Testing began once food intake stabilized $( \pm 10 \%$ food responding in the dark cycle for 3 consecutive days in the presence of water responding). For testing, nondeprived rats were pretreated before their daily 23 -h sessions with Ucn 3 using a full Latin square design with 3-4 intervening treatment-free days. During these treatment-free testing days, no residual or rebound changes in feeding were present, and carryover effects were not evident across testing days. Cages and bedding were not cleaned on the test day to avoid acute novelty stress effects.

For analysis of ingestive behavior, incremental food and water intake were calculated in $2 \mathrm{~h}$ time bins (1-2, $3-4,5-6 \mathrm{~h}$ ). Food intake was normalized for metabolic demands of different body weights (across and within subjects) according to Kleiber's 0.75 mass exponent (Kleiber and Rogers, 1961). Analysis of meal and bout microstructure were performed for the first $4 \mathrm{~h}$ of observation based on the time course of changes in intake.

For meal pattern analysis, an empirically validated, drinking-inclusive meal definition was used (Geary, 2005; Zorrilla et al, 2005a,b). Briefly, we recently showed that meals in rats are integrated units of feeding and drinking. Therefore, using arbitrary or log-survivorship analysis of inter-feeding intervals to define meals, as has been done previously, can lead to invalid conclusions regarding the microstructure of ingestion. In contrast, microstructure definitions that account for prandial drinking and acknowledge the log-normal distribution of inter-ingestion intervals within and between meals allow the microstructure of prandial food and water intake to be studied (Zorrilla et al, 2005a; Geary, 2005). Meals were defined as consecutive responses for food or water that contained at least five fooddirected responses $(0.225 \mathrm{~g}$ of food), greater than estimated lower bounds for meal size (Zorrilla et al, 2005a). The meal threshold breakpoint was calculated as the inter-event interval(s) between feeding- and drinking-directed behavior that provided the most stable joint estimates of meal size and meal duration, as described and validated previously (Zorrilla et al, 2005a). Based on this analysis, ingestive responses were considered to continue a meal if they 
occurred within $5 \mathrm{~min}$ of the previous response. Meals defined in this way are followed by the behavioral satiety sequence and conform to predictions of satiety (ie, a low initial probability of resuming feeding following meal termination which increases monotonically thereafter). In contrast, drinking-naïve meal definitions based on arbitrary or log-survivorship analysis of inter-feeding intervals are not similarly validated and can lead to misguided conclusions regarding the effects of treatments on the microstructure of ingestion (Zorrilla et al, 2005a,b). Defined in this manner (Zorrilla et al, 2005a), meals are hypothesized to be the unit of ingestion relevant to satiation (defined as the mechanism(s) through which feeding episodes come to end) and satiety (defined as the mechanism(s) through which completed feeding episodes are not subsequently resumed). Duration of eating and drinking within meals was defined separately as the duration of consecutive responses for food or water. Meal sizes for eating and drinking were calculated separately as the average number of food- or water-directed responses during meals. Rates of eating and drinking within meals were calculated by dividing each meal size with its respective duration.

To analyze changes in bout microstructure, a bout (the individual bursts of sustained feeding that collectively comprise a meal (Zorrilla et al, 2005b)) was defined as a sequence of at least three feeding responses in which no inter-feeding interval exceeded $35 \mathrm{~s}$. This bout threshold was established using frequency histogram analysis of logtransformed inter-feeding intervals to exclude almost all within-meal drinking pauses, while still including long nondrinking pauses within meals (see Zorrilla et al, 2005b). Thus, 'bouts' reflected within-meal episodes of sustained feeding that were not interrupted by prandial pauses (eg, to drink). Bouts reflect a lower-level organization of ingestive behavior than meals with the microstructure of bouts revealing the micro-control of food and water intake within meals. Although meals are hypothesized to be the unit relevant to the homeostatic control of food intake (Zorrilla et al, 2005a), bout microstructure can reveal other aspects of ingestive behavior, including whether feeding is sustained when present (for example, by positive drive processes such as hunger or perceived food palatability; Kissileff, 2000). Each rat's central tendency and, where appropriate, variability (within-subject means and SDs, respectively) were calculated for the number of feeding and drinking bouts, the size and duration of bouts, the rate of (ingestive) events within bouts, and the duration of interbout intervals.

To determine whether Ucn 3 altered the serial dependence or regularity of sustained feeding within bouts, return map analysis was performed on consecutive feeding responses. Return maps, also known as joint inter-event interval plots or Poincaré maps, are a nonlinear method of time series analysis that reveals the temporal organization of rhythmic and non-rhythmic physiologic phenomena occurring as discrete events in time (Dekhuijzen and Bagust, 1996; Li and Huston, 2002; Szücs et al, 2003). For return map analysis, each inter-feeding interval $\left(\mathrm{IFI}_{i}\right)$ in the time-series is scatter-plotted against its prior inter-feeding interval $\left(\mathrm{IFI}_{i \text { - }}\right.$ 1). Different underlying temporal organizations give rise to quantifiably different graphical return plots. For example, increased irregularity of serial events is observed as an increased spread, or diffuseness, of the return map, whereas more regular and rhythmic events are observed as a more densely focused cluster of points. Joint probability density distributions were calculated by convolving the points in the IFI return maps with a two-variate triangular function called the kernel. The half-width of the unity-volume triangular kernel (pyramid) served as a smoothing parameter, and it was set to $1.5 \mathrm{~s}$. The sampling resolution of the probability density distribution was $0.1 \mathrm{~s}$. These joint probability density distributions appear in a color-coded form with warmer colors (toward red) indicating higher local probabilities.

As a quantitative measure of the variability in the serial rate of ingestion, the normalized return map entropy $(H)$ was computed according to the formula:

$$
H=-\frac{\sum_{i, j}^{n} p_{i, j} \log _{2}\left(p_{i, j}\right)}{\log _{2}\left(n^{2}\right)}
$$

$H$ is normalized as a unitless index of the categorical variability in the joint probability distribution and scaled between 0 and 1 . The denominator of the expression is the logarithm of the total number of values used in the joint probability density distributions ( $n^{2}$ bins). Zero (minimal) entropy occurs when all events occur within a single bin space (ie, when only one bin has a non-zero probability, the most peaked distribution), whereas an $H=1$ (maximal entropy) occurs when each bin had an equal probability, or a flat uniform joint density distribution (Szücs et al, 2003). Entropy was calculated both for feeding and drinking, respectively, during the first $4 \mathrm{~h}$ after $\mathrm{Ucn} 3$ infusion into the VMN, PVN or MeA.

\section{Experimental Protocols}

Experiment 1 -Effects of lateral ventricle Ucn 3 on the microstructure of ingestion. Rats $(n=8)$ were pretreated $(20 \mathrm{~min})$ with $\operatorname{Ucn} 3(0,0.2,1.0,5.0 \mu \mathrm{g})$ into the $\mathrm{LV}$ and then returned to the microstructure test cages. A $20 \mathrm{~min}$ pretreatment interval was chosen for intraventricular injections because prior studies with Ucn 1 that used briefer pretreatment intervals $(5 \mathrm{~min}$ ) failed to reveal the full functional properties of the peptide as compared to slightly longer pretreatment intervals (30 min) (Spina et al, 2002). This may reflect the time needed for intraventricularly injected substances to diffuse into parenchyma beyond the most periventricular zones to slightly deeper brain sites. For example, it takes leptin only $\sim 2$ min to diffuse $200 \mu \mathrm{m}$ into third ventricular structures after lateral ventricle administration, but up to 30 min fully to reach a depth of $600 \mu \mathrm{m}$, needed to envelop the hypothalamic structures under study (Maness et al, 1998). During pretreatment intervals, rats were maintained in their familiar holding cages, used daily during apparatus maintenance, without food or water available.

Experiment 2-Conditioned taste aversion test after lateral ventricle Ucn 3. To determine whether anorectic doses of LV Ucn 3 produced a malaise-like state, individually housed rats $(n=21)$ were tested in a sensitive, 12-day, multiple-pairing, two-bottle choice conditioned taste aversion (CTA) procedure as described previously 
(Inoue et al, 2003). Briefly, rats were accustomed for 1 week to acquire their total daily fluid intake during brief, defined periods by providing rats limited (25-min) home cage access to two sipper tube bottles, each containing tap water beginning at $0930 \mathrm{~h}$. On days 8 and 10 (preconditioning and post-conditioning 1), rats had limited access to one bottle with a $7.31 \mathrm{mM} \mathrm{Na}$ saccharin solution $(0.15 \% \mathrm{w} / \mathrm{v}$; Sigma, St Louis, MO, USA) and one bottle with tap water. Immediately after saccharin access, subjects were administered $\operatorname{Ucn} 3(0,1$, or $5 \mu \mathrm{g} / 5 \mu \mathrm{l})$ into the LV in a betweensubjects design, receiving the same dose on each day. Tap water was available in both bottles on days 9 and 11. On day 12 (post-conditioning 2), each subject again chose between the saccharin solution and water in a treatment-free state. Initial position (side) of the saccharin bottle was counterbalanced across subjects and alternated daily thereafter. As a positive control, separate rats $(n=14)$ were administered isotonic $(0.15 \mathrm{M}) \mathrm{LiCl}$ (Sigma) or $\mathrm{NaCl}$ intraperitoneally $(20 \mathrm{ml} / \mathrm{kg})$ postsaccharin access instead of Ucn 3 . This dose of $\mathrm{LiCl}$ is known to induce taste aversion via gastrointestinal discomfort (Seeley et al, 2000; Inoue et al, 2003). A relative decrease in saccharin preference ratio is interpreted as the formation of a conditioned taste aversion.

Experiment 3 -Effects of Ucn 3 and $C R F_{2}$ antagonist treatment on free feeding. To test the hypothesis that the anorectic effects of $L V$ Ucn 3 reflected a $C_{2 R}$ receptormediated and central site of action, four groups of nondeprived rats were tested for free feeding in a between-subjects design. Each rat received a subcutaneous (s.c.) injection followed immediately by an LV infusion after which they were provided free access to preweighed food and water. Rats in group 1 ('vehicle'; $n=9$ ) received s.c. vehicle $(1 \mathrm{ml} / \mathrm{kg}$ bw of sterile water $)$ and $L V$ vehicle infusions ( $5 \mu$ l sterile water). Rats in group 2 ('central Ucn 3'; $n=9$ ) received s.c. vehicle and i.c.v. Ucn 3 infusions $(2.5 \mu \mathrm{g})$. To assess $\mathrm{CRF}_{2}$ receptor mediation, rats in group 3 ('central $\mathrm{Ucn} 3+\mathrm{CRF}_{2}$ antagonist'; $n=6$ ) received s.c. vehicle and $\mathrm{LV}$ cotreatment with $\mathrm{Ucn} 3(2.5 \mu \mathrm{g})$ and astressin $\sin _{2} \mathrm{~B}(10 \mu \mathrm{g})$, a selective $\mathrm{CRF}_{2}$ receptor antagonist (Rivier et al, 2002), which does not intrinsically increase food intake at the chosen dose. To assess central mediation of the anorectic effects of Ucn 3, rats in group 4 ('peripheral Ucn 3'; $n=8$ ) received the same $2.5 \mu \mathrm{g}$ dose of Ucn 3 , but by the s.c. route, as well as an LV infusion of vehicle.

Experiment 4-Effects of fourth ventricle Ucn 1 and Ucn 3 on free feeding. Experiment 4 tested the hypothesis that the potent anorectic effects of Ucn 3 that were observed after LV infusion of Ucn 3 in Experiments 1 and 3 reflected a hindbrain site of action. The effects of Ucn 3 pretreatment $(-20 \mathrm{~min})$ into the fourth ventricle $(0,0.5,2.5 \mu \mathrm{g} ; n$ 's $=8,7$, and 11 , respectively) on free feeding were tested in nondeprived rats using a between-subjects design. The higher dose of Ucn 3 was chosen because it suppressed feeding following infusion into the LV in Experiment 3 and also was slightly higher than the minimum effective LV dose in Experiment 1. Because Ucn 1 has previously been reported to suppress nocturnal food or sweetened solution intake following fourth ventricle administration (Grill et al, 2000; Daniels et al, 2004), separate groups of nondeprived rats received vehicle or $\operatorname{Ucn} 1(0,2.91 \mu \mathrm{g} ; n$ 's $=7$ and 9, respectively) into the fourth ventricle as a positive reference control. The dose of Ucn 1 was equimolar to the highest dose of Ucn 3 and in the range previously reported to reduce food intake after acute fourth ventricle infusion (Grill et al, 2000; Daniels et al, 2004). Preweighed food and water were provided and measured after 2 and $4 \mathrm{~h}$ of access. A between-subjects design was used due to experimental dropout, including lost cannulae and complications from repeated hindbrain injection. While this would reduce power relative to within-subjects designs, effect sizes (Cohen's $d$ ) for Ucn 3 were negligible following fourth ventricle administration as compared to after third ventricle or intra-hypothalamic administration, and significant effects were seen with the positive control Ucn 1 .

Experiment 5-Effects of intra-hypothalamic and intraamygdala Ucn 3 on the microstructure of ingestion. Experiment 5 tested the effects of site-specific microinfusion of Ucn 3 into the VMN, PVN, or MeA, candidate forebrain sites of $\mathrm{Ucn} 3-\mathrm{CRF}_{2}$ action as reviewed above, on the microstructure of ingestion. Ucn 3 was bilaterally microinjected $(0,0.1,0.5 \mu \mathrm{g} / 0.5 \mu \mathrm{l} /$ side, resulting in total doses $0,0.2$, and $1.0 \mu \mathrm{g}$ ) into the $\mathrm{VMN}, \mathrm{PVN}$, or $\mathrm{MeA}$ ( $n$ 's $=7,8$, and 6 ), and rats were then immediately returned to microstructure test cages.

Power analysis was used to quantify the power of the within-subjects design to detect changes in feeding. The current design is more powerful than a between-subjects design because of the large stable individual differences shown by Wistar rats in food intake and microstructure under the current test conditions. An average autocorrelation of 0.68 was estimated conservatively because even higher $r$ 's are observed across 3-week periods for most measures of food intake and meal microstructure (Zorrilla et al, 2005a). For a two-way 3 (Dose) $\times 3$ (Time) repeatedmeasure design, The Power Analysis and Sample Size (PASS) facility of Number Cruncher Statistical System (Hintze J, May 19, 2006 release) estimated maximal power $(\sim 1.00)$ to detect an effect size of 0.5 standard deviations for both main effects and interaction terms with an $n=6$, and very good power to detect an effect size as small as 0.3 standard deviations with an $n=8$ (power $\sim 0.95$ for main effects, $\sim 0.9$ for interaction) or even an $n=6$ (power $\sim 0.82$ for main effects, $\sim 0.75$ for interaction). To have the same power to detect a Dose $\times$ Time interaction of either effect size, a conventional between-subject two-way $3 \times 3$ design would have required a sample size $>50$.

\section{Statistical Analysis}

To determine the time course of the effects of Ucn 3 microinjection into the LV (experiment 1) or brain parenchyma (experiment 5) on food and water intake, separate two-way analyses of variance (ANOVAs) were performed, with Dose and Time (1-2, 3-4 and 5-6 h bins) as repeated measures. Based on the time course of changes in intake, ANOVAs were then used to analyze effects of Ucn 3 on meal and bout microstructure during the first $4 \mathrm{~h}$ of observation with Dose and Time (1-2, 3-4h bins), where applicable, as repeated measures. Within-subjects Newman-Keuls pairwise comparisons were used to interpret significant omnibus effects. To determine the effects of 
post-saccharin Ucn 3 infusion on the formation of a CTA for saccharin (experiment 2), saccharin preference ratios $(100 \times$ saccharin solution intake/total fluid intake) were analyzed using mixed ANOVA, with Conditioning (preconditioning, post-pairing 1, post-pairing 2) as a withinsubjects factor and Dose as a between-subjects factor. Appropriate within- or between-subjects Newman-Keuls contrasts were used to interpret treatment effects. To interpret the effects of $U \mathrm{cn} 3$ and $\mathrm{CRF}_{2}$ antagonist treatment on free feeding (experiment 3), Dunnett's tests were used to compare the effects of central and peripheral Ucn 3 treatments $v s$ the vehicle condition and of antagonisttreated subjects to the central Ucn 3-only condition. Data from the fourth ventricle free feeding experiments (experiment 4) were analyzed by separate mixed ANOVAs, with Time as a repeated measure and Dose as a between-subject measure. Dunnett's post hoc test was used to interpret significant effects relative to the vehicle condition.

The software packages used were SPSS 12.0 (SPSS, Chicago, IL, USA) and InStat 3.0 (GraphPad, San Diego, CA, USA). Bout microstructure and return map analyses were performed with the assistance of Orbital Spike 3.9 (http://www.blki.hu/szucs/OS3.html). All results are expressed as mean \pm SEM.

\section{RESULTS}

Experiment 1 - Effects of Lateral Ventricle Ucn 3 on the Microstructure of Nocturnal Ingestion

As shown in Figure 1a, LV infusion of Ucn 3 reduced incremental nocturnal food intake with delayed onset, as reflected in a significant Dose $\times$ Time interaction $\left(\mathrm{F}_{(6,42)}=3.78, p<0.005\right)$. Post hoc contrasts showed that 1 and $5 \mu \mathrm{g}$ doses of Ucn 3 reduced incremental food intake during the third-fourth hour of observation. Ucn 3 also reduced water intake during this period, reflected in a Dose $\times$ Time interaction $\left(\mathrm{F}_{(6,42)}=2.94, p<0.05\right)$, with post hoc comparisons finding that the $1 \mu \mathrm{g}$ dose reduced water intake relative to vehicle treatment (Figure $1 \mathrm{~b}$ ). Significant differences in incremental responding for food or water were not observed after the fourth hour of observation, so microstructure analyses were limited to the first $4 \mathrm{~h}$.

Table 1 shows the effect of LV infusion of Ucn 3 on 4-h meal microstructure. Meal pattern analyses indicated that Ucn 3 potently reduced meal frequency and meal size during the period of anorexia, as reflected by significant Dose effects during this time $\left(\mathrm{F}_{(3,21)}=3.11, p<0.05\right.$ and $\mathrm{F}_{(3,21)}=5.24, p<0.01$, respectively). Post hoc comparisons indicated that LV infusion of Ucn 3 more potently reduced
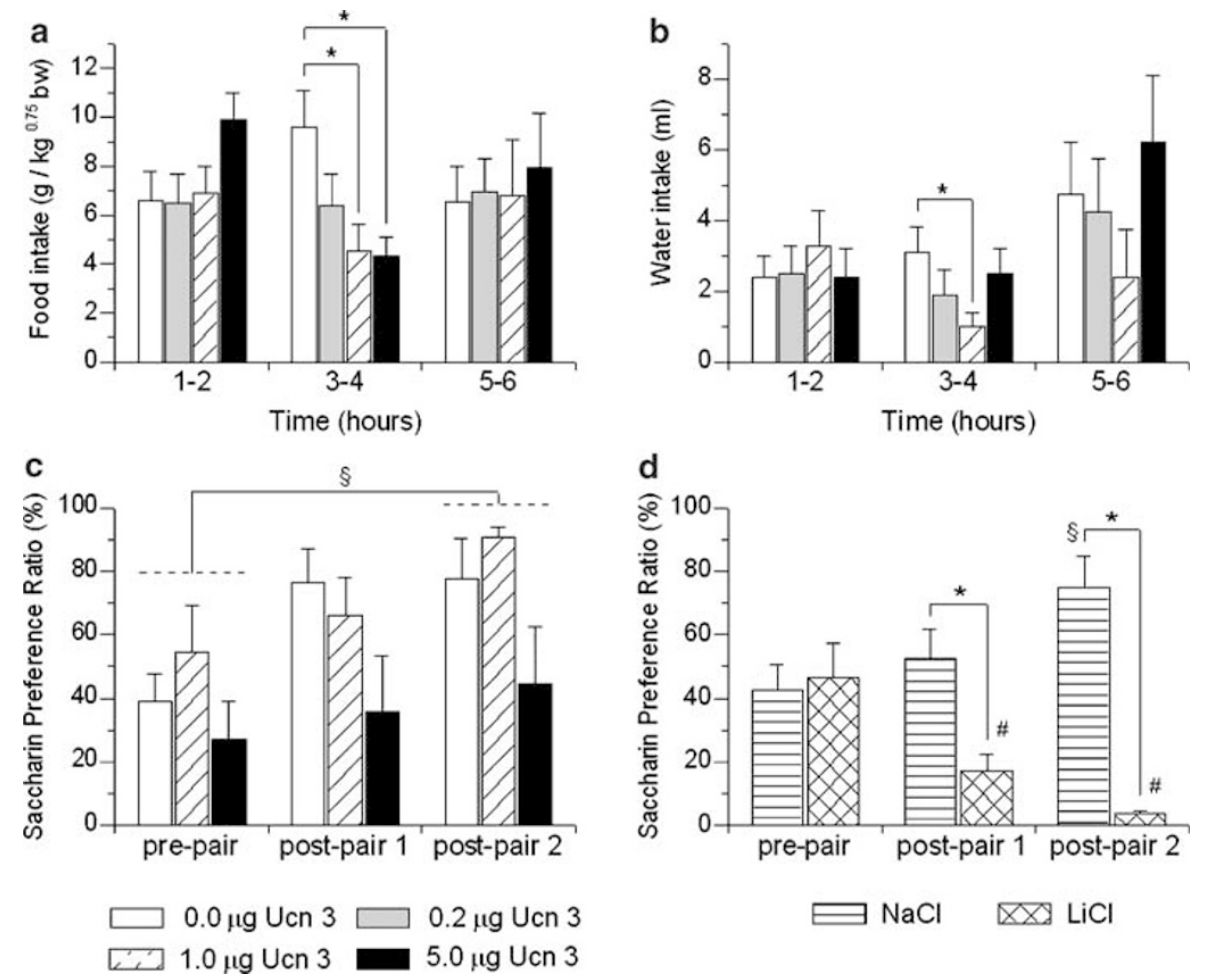

Figure I Effect of lateral ventricle (LV) pretreatment ( $-20 \mathrm{~min}$ ) with murine urocortin 3 (Ucn 3) on mean ( + SEM) incremental food (a) and water intake (b) in nondeprived, male Wistar rats $(n=8)$ housed in automated test cages that detect intake as nosepoke events (Experiment I). Food intake is normalized for body weight per Kleiber's mass exponent. ${ }^{*} p<0.05$ vs vehicle treatment (within-subject Newman-Keuls test). Panel (c) shows effects of LV injection of $U \mathrm{cn} 3$ on the formation of a conditioned taste aversion (CTA) (Experiment 2). Data are expressed as the mean (+ SEM) preference ratio for a $7.3 \mathrm{I} \mathrm{mM}$ saccharin solution over water as a function of having received LV Ucn 3 injections immediately after consuming the previously novel saccharin solution, ${ }^{\S_{p}}<0.05$, post-pair preference ratios were significantly higher than pre-pair preference ratios $(n=7 / g r o u p)$. Panel (d) shows effects of postsaccharin injections of the positive control $0.15 \mathrm{M} \mathrm{LiCl}$ (i.p., $20 \mathrm{ml} / \mathrm{kg}$ ) on the formation of a CTA for the otherwise palatable saccharin solution, as compared to rats receiving isotonic $\mathrm{NaCl}$. $\mathrm{LiCl}$, but not anorectic and hypodipsic doses of $\mathrm{Ucn} 3$, reliably produced a conditioned taste aversion. ${ }^{*} p<0.05$ vs $\mathrm{NaCl}$ injection, ${ }^{\#} p<0.05$ preconditioning (pre-pair) vs post-pairing (post-pair) preference ratio was significantly lower after LiCl injections, ${ }^{\$} p<0.05$, post-pair preference ratios were significantly higher than pre-pair preference ratios after $\mathrm{NaCl}$ injections ( $n=7 / g r o u p)$ (between-subject Newman-Keuls tests). 
Table I Effect of Lateral Ventricle (LV) Injection of Murine Ucn 3 on Meal Microstructure of Male Rats

\begin{tabular}{|c|c|c|}
\hline \multirow[b]{2}{*}{ Microstructure parameter } & \multicolumn{2}{|c|}{ Time bin (h) } \\
\hline & $\mathrm{I}-2$ & $3-4$ \\
\hline \multicolumn{3}{|l|}{ Meal frequency, no. of meals } \\
\hline $0 \mu g$ & $2.1 \pm 0.4$ & $2.5 \pm 0.3$ \\
\hline $0.2 \mu \mathrm{g}$ & $2.1 \pm 0.4$ & $1.4 \pm 0.3^{*}$ \\
\hline $1.0 \mu \mathrm{g}$ & $1.8 \pm 0.2$ & $1.4 \pm 0.2 * * *$ \\
\hline $5.0 \mu \mathrm{g}$ & $2.9 \pm 0.4$ & $1.6 \pm 0.3 *$ \\
\hline \multicolumn{3}{|l|}{ Average meal size } \\
\hline \multicolumn{3}{|l|}{ Food, g } \\
\hline $0 \mu \mathrm{g}$ & $1.7 \pm 0.3$ & $2.0 \pm 0.3$ \\
\hline $0.2 \mu \mathrm{g}$ & $1.7 \pm 0.3$ & $2.1 \pm 0.2$ \\
\hline $1.0 \mu \mathrm{g}$ & $2.0 \pm 0.4$ & $1.5 \pm 0.2$ \\
\hline $5.0 \mu \mathrm{g}$ & $1.8 \pm 0.3$ & $1.3 \pm 0.1 *$ \\
\hline \multicolumn{3}{|l|}{ Water, ml } \\
\hline $0 \mu \mathrm{g}$ & $1.6 \pm 0.6$ & $1.3 \pm 0.3$ \\
\hline $0.2 \mu \mathrm{g}$ & $1.0 \pm 0.5$ & $0.9 \pm 0.4$ \\
\hline $1.0 \mu \mathrm{g}$ & $1.9 \pm 0.6$ & $0.9 \pm 0.4$ \\
\hline $5.0 \mu \mathrm{g}$ & $1.0 \pm 0.3$ & $1.6 \pm 0.5$ \\
\hline \multicolumn{3}{|l|}{ Within-meal ingestion rate } \\
\hline \multicolumn{3}{|l|}{ Eating, mg/s } \\
\hline $0 \mu \mathrm{g}$ & $6.2 \pm 0.4$ & $6.1 \pm 0.3$ \\
\hline $0.2 \mu \mathrm{g}$ & $6.3 \pm 0.3$ & $6.3 \pm 0.4$ \\
\hline $1.0 \mu \mathrm{g}$ & $5.0 \pm 0.3^{*}$ & $5.9 \pm 0.4$ \\
\hline $5.0 \mu \mathrm{g}$ & $4.1 \pm 0.3^{* * *}$ & $6.0 \pm 0.5$ \\
\hline \multicolumn{3}{|l|}{ Drinking, $\mu \mathrm{l} / \mathrm{s}$} \\
\hline $0 \mu \mathrm{g}$ & $9.7 \pm 2.1$ & $9.1 \pm 2.4$ \\
\hline $0.2 \mu \mathrm{g}$ & $10.8 \pm 2.5$ & $11.2 \pm 2.2$ \\
\hline $1.0 \mu \mathrm{g}$ & $9.4 \pm 1.8$ & $10.5 \pm 2.4$ \\
\hline $5.0 \mu \mathrm{g}$ & $9.0 \pm 2.5$ & $6.9 \pm 1.0$ \\
\hline
\end{tabular}

Asterisks indicate significant differences from vehicle condition, $* p<0.05$, *** $p<0.01$.

meal frequency than meal size, as each dose of Ucn 3 reduced meal frequency relative to the vehicle condition during the third-fourth hour of observation, whereas only the $5 \mu \mathrm{g}$ dose reliably reduced meal size (see Table 1 ). LV infusion of Ucn $3(1,5 \mu \mathrm{g})$ also slowed the rate of sustained eating within meals during the $1-2 \mathrm{~h}$ time bin, or before the onset of anorexia $\left(\mathrm{F}_{(3,21)}=4.19, p<0.05\right)$. This effect was behaviorally specific as the concurrent rate of drinking was unaffected (see Table 1).

\section{Experiment 2-No Conditioned Taste Aversion After Lateral Ventricle Ucn 3}

Anorectic doses of Ucn $3(1,5 \mu \mathrm{g})$ did not induce a reliable CTA, as indicated by no significant Dose $\times$ Conditioning interaction and by no reliable main effect of Dose. Figure 1c illustrates that the minimal effective anorectic dose of Ucn 3 infused into the LV (1 $\mu \mathrm{g})$ showed no tendency to decrease saccharin preference ratios. Rather, as with vehicle-treated subjects, saccharin preference ratios increased significantly in Ucn 3-treated rats after they experienced access to the sweet solution (compare pre-pair vs post-pair 2 in Figure 1, $p<0.05)$. The increment in saccharin preference ratio was slightly, but not significantly, slowed or blunted at the highest Ucn 3 dose.

Using the same procedure, and as expected, post-access treatment with $\mathrm{LiCl}$, the positive control for malaise, markedly reduced the preference ratio for $7.31 \mathrm{mM}$ saccharin, inducing a CTA after one pairing that was maintained with two pairings (Figure 1d). Mixed ANOVA revealed a significant Treatment $(\mathrm{LiCl} v s$ $\mathrm{NaCl}) \times$ Conditioning interaction $\left(\mathrm{F}_{(2,24)}=9.42, p=0.001\right)$. Post hoc contrasts indicated that LiCl-treated subjects had a significantly lower preference ratio than NaCl-treated subjects at the post-pairing 1 and post-pairing 2, but not preconditioning, time points. The difference reflected that significant increases in saccharin preference ratio occurred in NaCl-treated subjects from preconditioning to postpairing 2, whereas LiCl-treated subjects decreased their preference ratios from preconditioning to post-pairing 1 , with a further decrement observed from post-pairing 1 to post-pairing 2 (Figure 1d).

\section{Experiment 3-Effects of Ucn 3 and $\mathrm{CRF}_{2}$ Antagonist Treatment on Nocturnal Free Feeding}

The 'central Ucn 3' treated group (s.c. $0.0 \mu \mathrm{g} / \mathrm{LV} 2.5 \mu \mathrm{g}$ ) differed significantly from every other group in cumulative nocturnal $4 \mathrm{~h}$ intake, a difference that reflected the actions of Ucn 3 to reduce incremental food intake during the third-fourth hour of observation (Figure 2a). Thus, LV application of Ucn 3 caused delayed anorexia, an effect that was reversed by cotreatment with astressin $\sin _{2}-\mathrm{B}$, a selective $\mathrm{CRF}_{2}$ receptor antagonist. Subcutaneous administration of the same dose of Ucn 3 did not similarly reduce food intake (Figure 2a), further suggesting a central site of action.

\section{Experiment 4-Effects of Fourth Ventricle Ucn 1 and Ucn 3 on Nocturnal Free Feeding}

Fourth ventricle administration of Ucn $3(0.5,2.5 \mu \mathrm{g})$ did not produce nocturnal hypophagia (Figure $2 \mathrm{~b}$ ) (repeated measures ANOVA; for $1-2 \mathrm{~h}: \mathrm{F}_{(2,12)}=0.061, p=0.94$; for $3-4 \mathrm{~h}: \mathrm{F}_{(2,12)}=0.83, p=0.46$; for $1-4 \mathrm{~h}: \quad F_{(2,12)}=0.68$, $p=0.53$ ) or hypodipsia at any time point (repeated measures ANOVA; for $1-2 \mathrm{~h}: \mathrm{F}_{(2,12)}=0.14, p=0.864$; for $3-4 \mathrm{~h}: \mathrm{F}_{(2,12)}=0.01, \quad p=0.990$; for $1-4 \mathrm{~h}: \mathrm{F}_{(2,12)}=0.06$, $p=0.936$; data not shown). The higher dose of Ucn 3 infused $(2.5 \mu \mathrm{g})$ was inactive despite being in the range that had produced anorexia in Experiments 1 and 3 following LV administration. In contrast, equimolar application of Ucn 1 $(2.91 \mu \mathrm{g})$ into the fourth ventricle significantly reduced incremental food intake during the $3-4 \mathrm{~h}$ bin (Figure $2 \mathrm{c}$ ) $\left(\mathrm{F}_{(1,6)}=9.42, p<0.05\right)$ without reliably altering water intake at any time point (repeated measures ANOVA; for $1-2 \mathrm{~h}$ : $\mathrm{F}_{(1,6)}=3.12, p=0.13$; for $3-4 \mathrm{~h}: \mathrm{F}_{(1,6)}=0.51, p=0.50$; for $1-4$ h: $\mathrm{F}_{(1,6)}=2.83, p=0.14$; data not shown). 

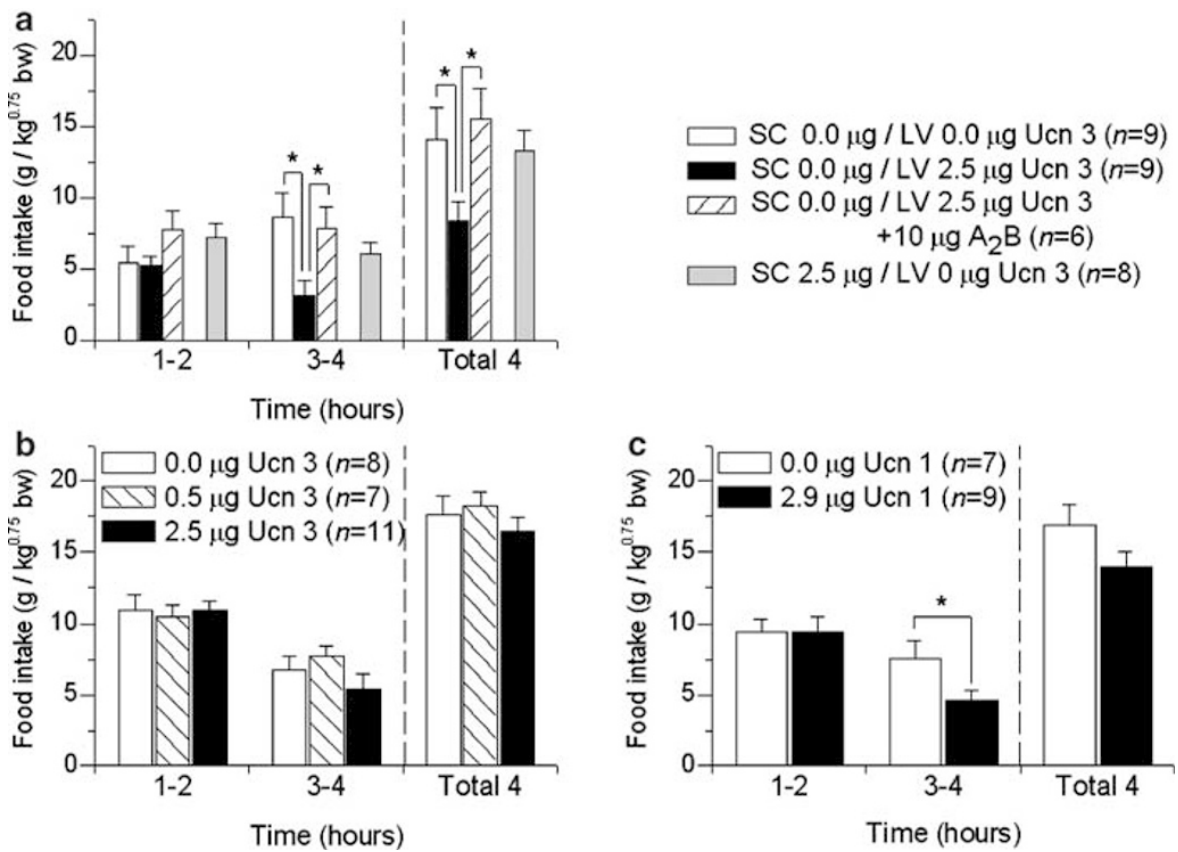

Figure 2 Panel (a) shows that adult male, ad libitum fed Wistar rats receiving lateral ventricle $(L V)(n=9)$, but not subcutaneous (s.c.), injection of $2.5 \mu \mathrm{g}$ murine $U \mathrm{cn} 3(n=8)$ ate less in the subsequent $4 \mathrm{~h}$ than vehicle-treated subjects $(n=9)$ (Experiment 3$)$. This effect was blocked by $L V$ cotreatment with astressin ${ }_{2} B\left(A_{2} B\right)$, a selective $C R F_{2}$ antagonist $(n=6)$. Each rat received a s.c. injection $(0.0,2.5 \mu \mathrm{g} \cup \mathrm{cn} 3)$ followed immediately by an LV injection $(0.0,2.5 \mu \mathrm{g}$ $U_{\mathrm{cn}} 3$, or $2.5 \mu \mathrm{g} U \mathrm{cn} 3+10 \mu \mathrm{g} \mathrm{A}_{2} \mathrm{~B}$ ) during the early portion of the dark cycle followed by free access to preweighed chow. Data are expressed as mean (+ SEM) food intake normalized for body weight per Kleiber's mass exponent. Time course analysis showed an anorectic effect in the second $2 \mathrm{~h}$ postinjection bin. $* p<0.05$, the s.c. $0.0 \mu \mathrm{g} / \mathrm{LV} 2.5 \mu \mathrm{g}$ ('central Ucn 3') group differed significantly from every other group at the total 4 and 3-4h periods (Dunnett's test). Panels (b) and (c) show effect of fourth ventricle injection of murine Ucn 3 (b) or human Ucn I (c) on nocturnal free feeding in ad libitum fed male Wistar rats (Experiment 4). The $2.9 \mu$ g dose of $U \mathrm{cn}$ I is equimolar to the $2.5 \mu \mathrm{g}$ dose of $U \mathrm{cn} 3$. *p $<0.05$, the $2.9 \mu \mathrm{g} U \mathrm{cn}$ I group significantly differs from vehicle group (between-subject Dunnett's test).

\section{Experiment 5-Effects of Intra-Hypothalamic and Intra-Amygdala Ucn 3 on the Microstructure of Nocturnal Ingestion}

The i.c.v. experiments indicated that Ucn 3 more potently produced delayed nocturnal anorexia and hypodipsia after LV infusion than after fourth ventricle infusion, suggesting a forebrain site of action. The site-specific infusion studies in Experiment 5 were designed to compare the effects of local Ucn 3 microinfusion into candidate hypothalamic and amygdala forebrain sites that contain proximate $\mathrm{Ucn} 3-\mathrm{CRF}_{2}$ expression. Figure 3 illustrates a map of actual injection sites for injections deemed to have correct ('hits') and incorrect ('misses') bilateral placements for intra-parenchymal injections into the VMN, PVN, or MeA. The number of rats with VMN, PVN, and MeA hits were 7, 8, and 6, respectively (Figures 3a-c and 4). As shown in Figures 3 and 4, VMN 'hits' lay in its dorsomedial subdivision, where $\mathrm{CRF}_{2}$ receptors and Ucn 3-IR fibers are most densely expressed, at both its rostral and caudal extents. PVN 'hits' tended to be along its most dorsolateral, less rostral extent, and appeared to include placements in dorsal and lateral parvocellular and posterior magnocellular subdivisions. MeA 'hits' were localized in the posterodorsal medial amygdala, where $\mathrm{CRF}_{2}$ receptors and Ucn 3 are densely expressed, clearly having perforated the optic tract. Perhaps because of the relative homogeneity of defined 'hits' and the injection volumes used, subtle differences between place- ments within a brain site were not associated with functional differences, so they are collectively described below.

Total quantity of intake. Figure 5 shows food intake after local infusion of Ucn 3 into the VMN (Panel a), PVN (b), or MeA (c). As shown in Figure 4a and b, intra-hypothalamic Ucn 3 infusion reduced incremental food intake during the third-fourth hours of observation, as reflected in a main effect of Dose $\left(\mathrm{F}_{(2,12)}=8.72, p<0.005\right)$ and a Dose $\times$ Time interaction $\left(\mathrm{F}_{(4,24)}=3.51, p<0.025\right)$ for the $\mathrm{VMN}$ and a significant effect of Dose for the PVN $\left(\mathrm{F}_{(2,14)}=6.00\right.$, $p=0.01)$. Post hoc tests indicated that both doses of Ucn $3(0.1,0.5 \mu \mathrm{g})$ significantly reduced intake relative to vehicle treatment $(p<0.05)$. In contrast, intra-MeA infusion of Ucn 3 did not reduce total food intake during any time bin (Figure 5c).

Figure 5 also shows water intake (d, e, f) after local infusion of Ucn 3 into the VMN (d), PVN (e), or MeA (f). As illustrated in Figure 5d and e, intra-hypothalamic Ucn 3 infusion also reduced incremental water intake during the 3-4 $\mathrm{h}$ time bin, as indicated by significant Dose effects in the VMN $\left(\mathrm{F}_{(2,12)}=7.15, p<0.009\right)$ and PVN $\left(\mathrm{F}_{(2,14)}=4.00\right.$, $p<0.05)$. Post hoc tests found that $0.1 \mu \mathrm{g}$ bilateral infusion of Ucn 3 into the VMN $(p<0.01)$ or PVN $(p<0.05)$ decreased water intake during this period. Water intake decreased during the 5-6h time bin, but not earlier, following intra-MeA infusion and only after the highest 
dose of Ucn $3(0.5 \mu \mathrm{g})\left(\mathrm{F}_{(2,10)}=6.83, p=0.01\right.$; NewmanKeuls: $p<0.05$, Figure $5 f$ ).

The number of rats with misses was 5,4 , and 2 for the VMN, PVN, and MeA, respectively (see Figure 3d-f). VMN 'misses' were most often anterior to the VMN, within or medial to the ventral anterior hypothalamus; or in the third ventricle; with one placement just ventral to the dorsome-

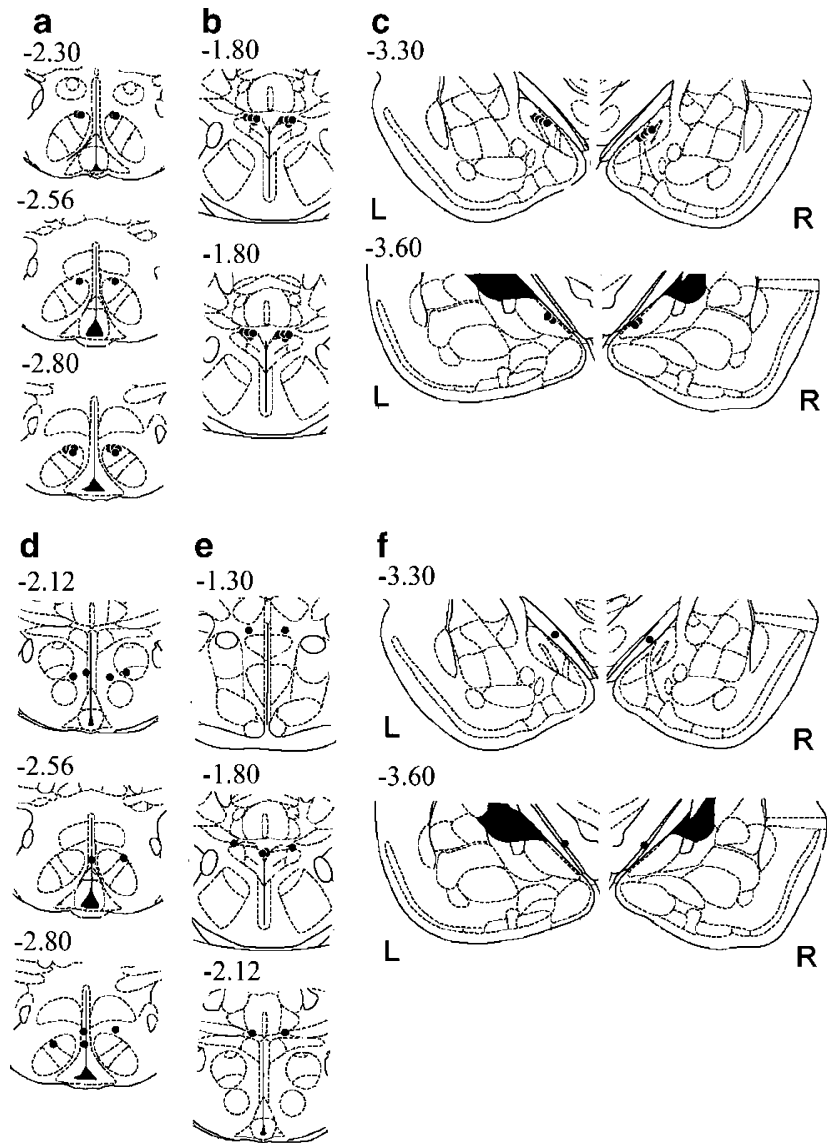

Figure 3 Illustration of reconstructed injection sites from Experiment 5. Correct bilateral injection placements ('hits') are indicated as closed circles in the ventromedial (VMN; $n=7)$, paraventricular nuclei of the hypothalamus (PVN; $n=8)$, and medial amygdala $(M e A ; n=6)$ (panels a, $\mathrm{b}$ and $\mathrm{c}$, respectively). Incorrect injection placements ('misses') are indicated in panels (d), (e) and ( $f$ for the VMN $(n=5), \operatorname{PVN}(n=4)$, and MeA $(n=2)$, respectively. Brain structure diagrams of coronal sections are adapted from Paxinos and Watson (Paxinos and Watson, 1998), the numbers refer to anterior-posterior distance from bregma in $\mathrm{mm}$, L: left, R: right side of the brain. dial nucleus, and two excessively lateral placements approaching the ventrolateral VMN. PVN 'misses' were consistently too dorsal, along its full rostral-caudal extent. MeA 'misses' also were consistently too dorsal and failed to penetrate the optic tract, residing within the supraoptic decussation or internal capsule. In contrast to animals with correct placements, subjects with incorrect intra-parenchymal placements did not show trends for decreased food or water intake during the $1-2$ or $3-4 \mathrm{~h}$ time bins. Furthermore, of 'misses,' four animals had an incorrect injector placement within the third ventricle. This 'third ventricle' subgroup also did not exhibit significant changes in food or water intake within the first $4 \mathrm{~h}$. Subjects with an inadvertent third ventricle placement, however, did exhibit decreased food intake after the $0.5 \mu \mathrm{g}$, but not $0.1 \mu \mathrm{g}$, dose of Ucn 3 during the later $7-8 \mathrm{~h}$ time bin, as reflected in Dose $\left(\mathrm{F}_{(2,6)}=12.11, \quad p<0.008\right)$ and Dose $\times$ Time effects $\left(\mathrm{F}_{(6,18)}=2.95, p<0.05\right)$, with post hoc tests indicating that the $0.5 \mu \mathrm{g}$ condition decreased intake relative to the vehicle and $0.1 \mu \mathrm{g}$ conditions (data not shown). In these subjects, the $0.5 \mu \mathrm{g}$, but not $0.1 \mu \mathrm{g}$, dose also decreased incremental water intake during the $5-6,7-8$, and $9-10 \mathrm{~h}$ of observation, as reflected in Dose $\left(\mathrm{F}_{(2,6)}=30.47, p<0.001\right)$, and Dose $\times$ Time effects $\left(\mathrm{F}_{(8,24)}=7.28, p<0.0001\right)$. Post hoc tests indicated that the high dose of Ucn 3 reduced water intake relative to the vehicle and $0.1 \mu \mathrm{g}$ conditions during these periods ( $p$ 's $<0.05-0.001)$ (data not shown). Thus, intraVMN and intra-PVN infusion of Ucn 3 reduced food and water intake more potently or earlier than did infusion of Ucn 3 into the LV, third or fourth ventricles, or than intraMeA infusion of Ucn 3.

Total duration of meals. As shown in Table 2, intrahypothalamic Ucn $3(0.1 \mu \mathrm{g})$ also reduced the overall duration of meal-taking during the third-fourth hour of observation. Intra-VMN Ucn 3 infusion significantly decreased the time spent feeding, drinking, and transitioning between feeding and drinking. Similar trends were evident following intra-PVN infusion, with reductions in the duration of feeding reaching significance $(0.1,0.5 \mu \mathrm{g})$. In contrast, intra-MeA infusion of the same doses of Ucn 3 did not reduce the duration of prandial feeding. That is, although the higher dose of intra-MeA Ucn 3 reduced the overall duration of meal-taking $(0.5 \mu \mathrm{g})$, it did so by reducing the duration of drinking and transitioning between feeding and drinking, without influencing the time spent feeding (see Table 2).
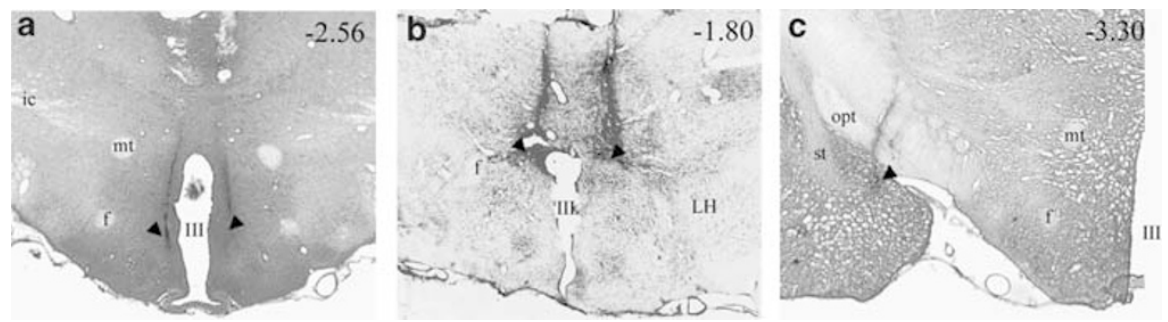

Figure 4 Light photomicrograph of coronal brain sections showing example of injector placements (black arrowheads) within (panel a) the dorsomedial subdivision of the ventromedial hypothalamic nucleus (VMN), (b) the dorsal aspect of the paraventricular nucleus of the hypothalamus (PVN), and (c) the posterodorsal medial amygdala (MeA). Numbers (top right of each panel) indicate approximate anterior-posterior distance from bregma in mm. Ic, internal capsule; f, fornix; LH, lateral hypothalamus; $m t$, medial tubercle; opt, optic tract; st, stria terminalis; III, third ventricle. 

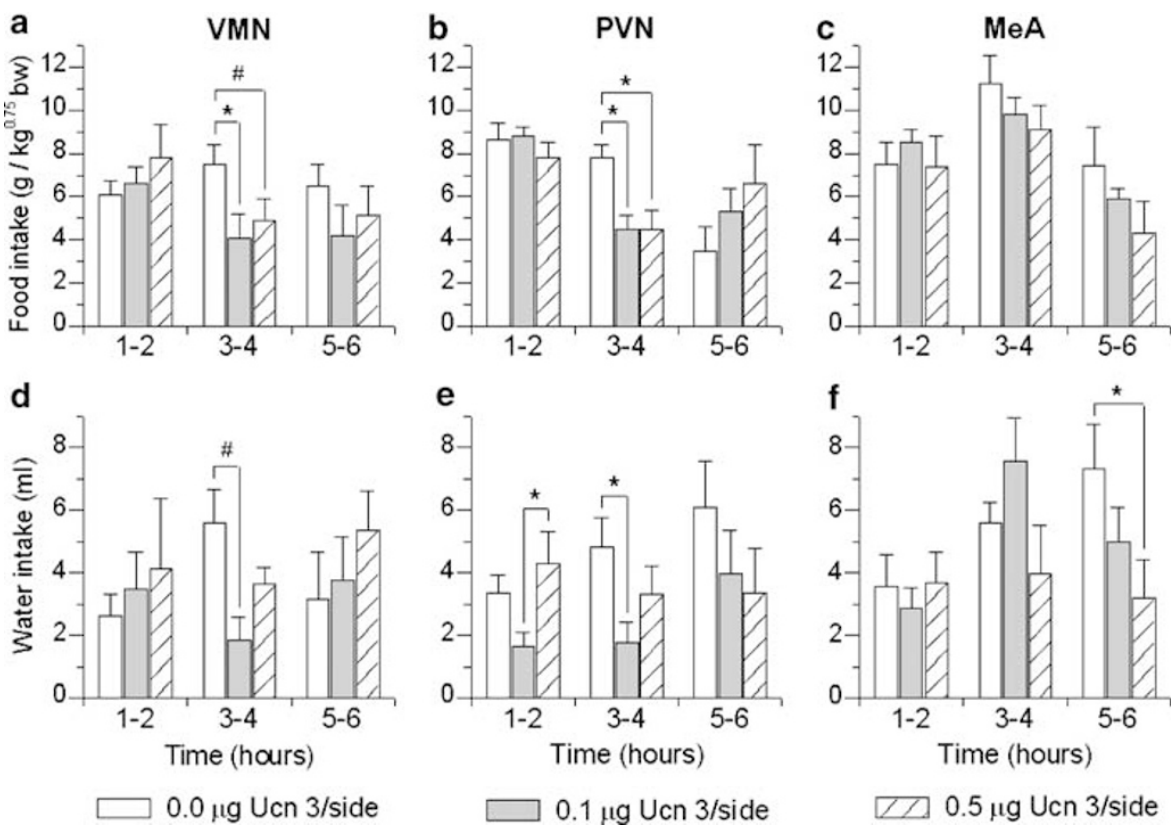

$0.1 \mu \mathrm{g} \mathrm{Uan} 3 / \mathrm{side}$

LC $0.5 \mu \mathrm{g}$ Ucn $3 /$ side

Figure 5 Effect of brain site-specific injections of murine urocortin 3 ( Ucn 3) on mean ( + SEM) incremental food and water intake in nondeprived, male Wistar rats housed in automated test cages that detect intake as nosepoke events (Experiment 5). Food intake is normalized for body weight per Kleiber's mass exponent. Intake is shown in 2-h bins following bilateral injection into the ventromedial (VMN; $n=7$ ) (panels a: food and d: water), paraventricular nuclei of the hypothalamus (PVN; $n=8$ ) (b: food, e: water), or medial amygdala (MeA; $n=6$ ) (c: food, f: water). ${ }^{\#} p<0.01$, ${ }^{*} p<0.05$ compared to vehicle (within-subjects Newman-Keuls test).

Table 2 Effect of Site-Specific Murine Ucn 3 Infusions on Duration of Prandial Ingestion of Male Rats

\begin{tabular}{|c|c|c|c|c|c|c|}
\hline \multirow[b]{2}{*}{ Total duration of meals, min } & \multicolumn{2}{|c|}{$\begin{array}{l}\text { Ventromedial nucleus of the } \\
\text { hypothalamus (VMN) }\end{array}$} & \multicolumn{2}{|c|}{$\begin{array}{l}\text { Paraventricular nucleus of the } \\
\text { hypothalamus (PVN) }\end{array}$} & \multicolumn{2}{|c|}{ Medial amygdala (MeA) } \\
\hline & $I-2 h$ & $3-4 h$ & $I-2 h$ & $3-4 h$ & $I-2 h$ & $3-4 h$ \\
\hline \multicolumn{7}{|l|}{ Overall } \\
\hline $0 \mu g$ & $18.5 \pm 2.9$ & $24.9 \pm 3.3$ & $25.5 \pm 4.1$ & $24.7 \pm 5.5$ & $32.4 \pm 6.8$ & $42.6 \pm 4.2$ \\
\hline $0.1 \mu \mathrm{g}$ & $24.0 \pm 5.0$ & $11.7 \pm 2.3^{*}$ & $21.5 \pm 3.3$ & $11.5 \pm 3.4 *$ & $34.7 \pm 5.5$ & $37.0 \pm 6.7$ \\
\hline \multicolumn{7}{|l|}{ Feeding } \\
\hline $0 \mu \mathrm{g}$ & $11.2 \pm 1.3$ & $10.9 \pm 0.8$ & $9.1 \pm 1.4$ & $11.1 \pm 1.4$ & $10.6 \pm 1.5$ & $17.0 \pm 1.4$ \\
\hline $0.1 \mu \mathrm{g}$ & $13.0 \pm 2.0$ & $6.6 \pm 1.0 *$ & $12.0 \pm 2.1$ & $6.6 \pm 1.8^{*}$ & $14.0 \pm 2.0$ & $16.7 \pm 2.0$ \\
\hline $0.5 \mu \mathrm{g}$ & $11.7 \pm 1.2$ & $8.6 \pm 2.4$ & $14.9 \pm 1.7^{*}$ & $6.9 \pm 1.5^{*}$ & $11.2 \pm 2.4$ & $14.0 \pm 2.3$ \\
\hline \multicolumn{7}{|l|}{ Drinking } \\
\hline $0.1 \mu \mathrm{g}$ & $8.4 \pm 3.7$ & $2.0 \pm 0.8 *$ & $3.5 \pm 1.2$ & $2.4 \pm 1.0$ & $11.5 \pm 2.5$ & $14.8 \pm 4.0$ \\
\hline $0.5 \mu \mathrm{g}$ & $7.6 \pm 3.9$ & $4.9 \pm 2.0$ & $8.0 \pm 2.1$ & $5.6 \pm 1.6$ & $10.2 \pm 6.5$ & $8.1 \pm 3.8$ \\
\hline \multicolumn{7}{|l|}{ Transitions } \\
\hline $0 \mu \mathrm{g}$ & $4.6 \pm 1.6$ & $6.1 \pm 1.1$ & $8.8 \pm 1.9$ & $5.0 \pm 1.2$ & $8.3 \pm 2.9$ & $9.9 \pm 1.8$ \\
\hline $0.1 \mu \mathrm{g}$ & $2.7 \pm 0.9$ & $3.1 \pm 1.4 *$ & $6.0 \pm 1.9$ & $2.5 \pm 1.0$ & $9.2 \pm 1.7$ & $5.5 \pm 1.5$ \\
\hline $0.5 \mu \mathrm{g}$ & $4.8 \pm 1.3$ & $4.0 \pm 0.7$ & $7.4 \pm 1.7$ & $4.0 \pm 0.9$ & $5.1 \pm 1.4$ & $4.8 \pm 2.0$ \\
\hline
\end{tabular}

Asterisks indicate significant differences from vehicle condition, $* 00.05$.

Meal microstructure. As shown in Table 3, local microinfusion of Ucn 3 altered meal microstructure in a sitespecific manner. Following both doses of Ucn 3 , intra-VMN injections reduced meal frequency during the $3-4 \mathrm{~h}$ time bin (the period of anorexia), as reflected in a significant Dose $\times$ Time interaction $\left(\mathrm{F}_{(2,12)}=5.38, p<0.025\right)$. Post hoc 
Table 3 Effect of Site-Specific Murine Ucn 3 Infusions on Meal Microstructure of Male Rats

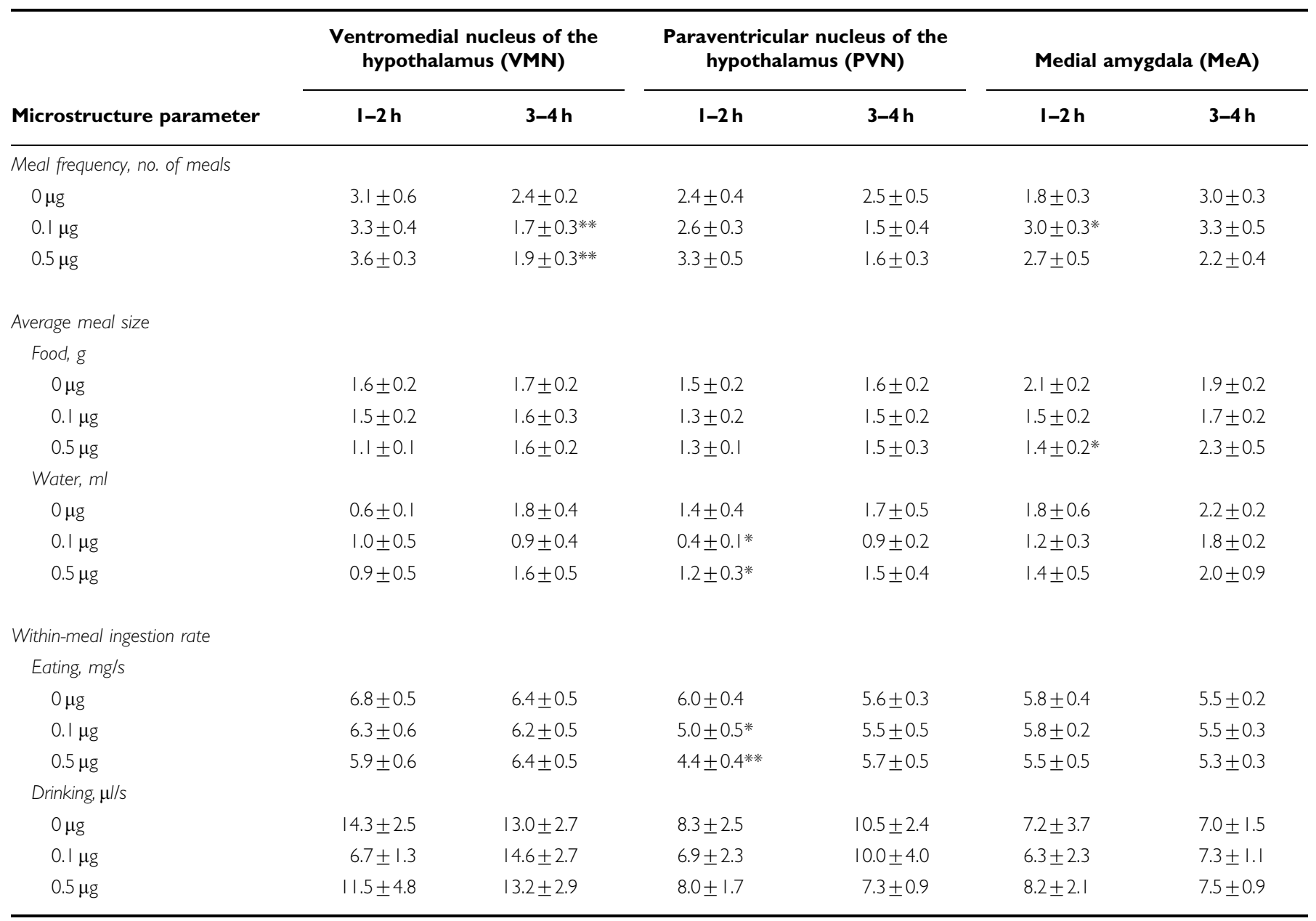

Asterisks indicate significant differences from vehicle condition, ${ }^{*} p<0.05, * * p<0.01$.

tests indicated that both doses of Ucn 3 significantly reduced meal frequency relative to vehicle treatment (Table 3). Intra-PVN Ucn 3 infusion also tended to reduce meal frequency during the $3-4 \mathrm{~h}$ time bin, as reflected in a trend for a Dose $\times$ Time interaction following intra-PVN infusion $\left(\mathrm{F}_{(2,14)}=3.07, p<0.08\right.$; see Table 2$)$. Consistent with these findings, both intra-PVN $(0.1,0.5 \mu \mathrm{g} / \mathrm{side})$ and intra-VMN $(0.1 \mu \mathrm{g} / \mathrm{side})$ infusion of Ucn 3 significantly prolonged the post-meal interval (see Figure 6a). In contrast, intra-MeA Ucn 3 infusion did not reduce meal frequency (Table 3) or alter the post-meal interval (Figure 6a) during the 3-4 h time bin, but rather increased meal frequency during the $1-2 \mathrm{~h}$ time bin $\left(\mathrm{F}_{(2,10)}=3.40\right.$, $p<0.04$; see Table 3$)$. This action of Ucn 3 did not reflect an overall orexigenic effect, because intra-MeA Ucn 3 infusion also concurrently reduced meal size $\left(\mathrm{F}_{(2,10)}=4.59, p<0.04\right)$, such that total intake did not change (Figure $3 \mathrm{c}$ ). Thus, intra-MeA Ucn 3 acutely promoted a nibbling pattern of smaller, but more frequent meals, relative to vehicle conditions, which contrasted with the delayed actions of intra-hypothalamic Ucn 3 to reduce meal frequency by prolonging post-meal intervals. Unlike the meal size reducing effect of intra-MeA Ucn 3, intra-PVN administration of Ucn 3 did not reliably alter meal size at the tested doses, and a $0.5 \mu \mathrm{g}$ dose within the $\mathrm{VMH}$ only tended to reduce meal size (see Table 3 ).

Similar to what was observed following $\mathrm{LV}$ infusion, intra-PVN infusion of Ucn 3 slowed the average rate of sustained eating within meals during the $1-2 \mathrm{~h}$ time bin, or prior to the onset of anorexia. This was observed in Dose $\left(F_{(2,10)}=4.34, p<0.05\right)$ and Dose $\times$ Time effects $\left(\mathrm{F}_{(2,10)}=12.99, p<0.002\right)$ (see Table 3$)$. The slowed rate of eating reflected that rats receiving $U \mathrm{cn} 3$ into the PVN took significantly longer to consume a comparable amount of food as they ate under vehicle conditions (Figure $4 \mathrm{~b}$; see Table 2; Dose $\times$ Time interaction: $\left.\mathrm{F}_{(2,14)}=4.20, p<0.05\right)$. Slower eating was behaviorally specific, as intra-PVN Ucn 3 did not influence the drinking rate. During the same time that PVN Ucn 3 infusion slowed the rate of eating, it also decreased the average amount of water drunk within each meal, as reflected in significant Dose effects during the first-second hour of observation $\left(\mathrm{F}_{(2,8)}=5.88, p<0.03\right.$, see Table 3).

Bout microstructure. To help interpret the finding that Ucn 3 slowed the eating rate within meals and to provide additional information on the effects of Ucn 3 on the lowlevel control of ingestion, microstructure analysis of bouts 

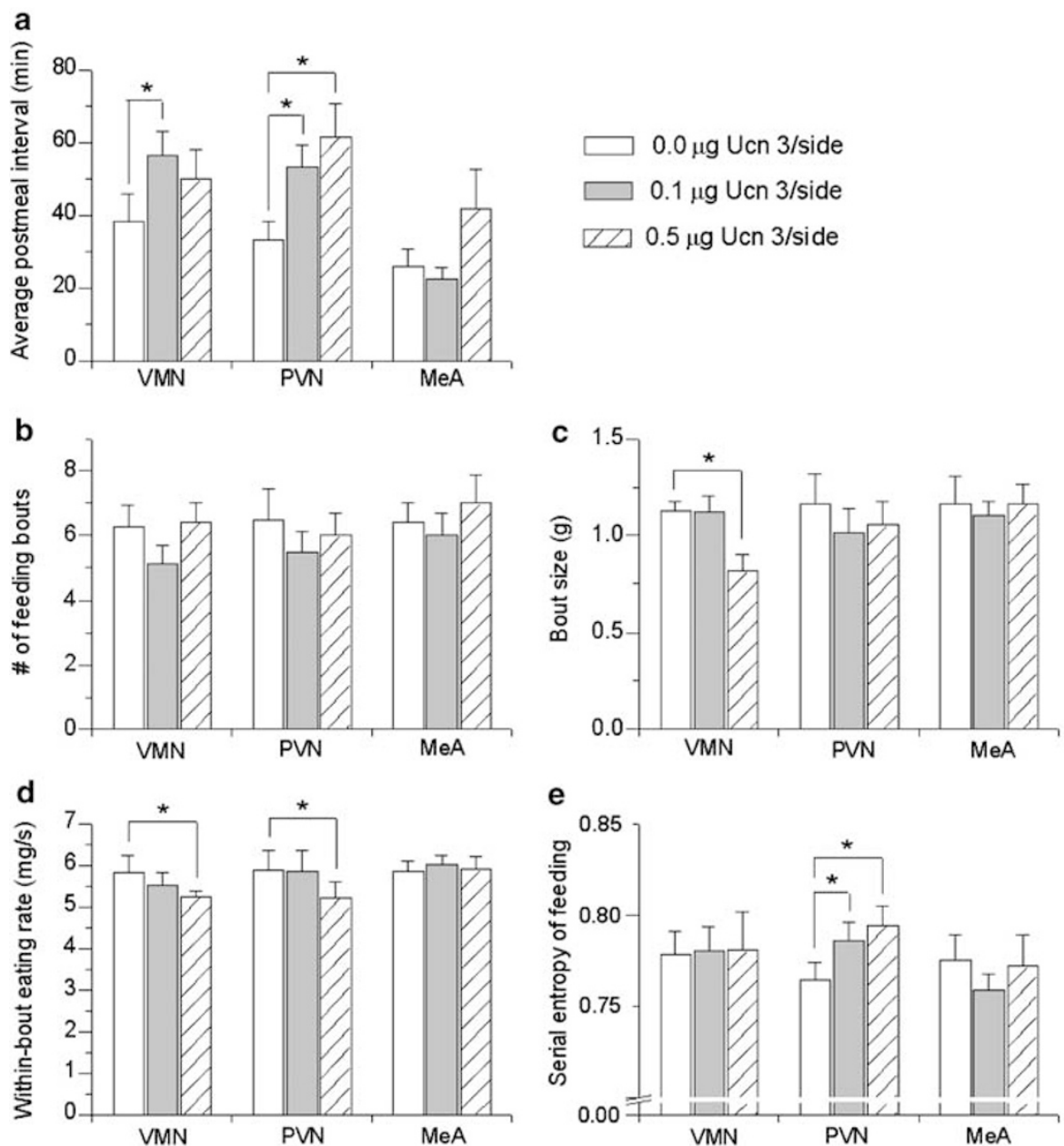

Figure 6 Effect of bilateral injection of murine Ucn 3 into the ventromedial (VMN; $n=7$ ), paraventricular nuclei of the hypothalamus (PVN; $n=8)$, or medial amygdala (MeA; $n=6$ ) on the mean ( $\mathrm{SEM}$ ) average post-meal interval during the third-fourth post-injection hours (a) and on aspects of feeding bout microstructure (b-e) during the first 4 post-injection hours. Intra- $\mathrm{VMH}$ and PVN treatment prolonged the post-meal interval during the period of anorexia (a). No treatment altered the number of feeding bouts (b), but intra-VMH Ucn 3 infusion reduced the average bout size (c) and slowed the withinbout eating rate (d). Intra-PVN Ucn 3 infusion also slowed the within-bout eating rate and increased the serial irregularity of feeding within bouts, calculated as the entropy of the probability joint return map for feeding (e). Based on log-transformed frequency histogram analysis of inter-feeding and inter-drinking intervals, a feeding bout was defined as three or more feeding events in which consecutive feeding events were $<35 \mathrm{~s}$ apart. $* p<0.05$ vs within-subjects vehicle treatment.

was performed. Intra-PVN and also intra-VMN Ucn 3 $(0.5 \mu \mathrm{g} / \mathrm{side})$ significantly slowed the rate of eating within feeding bouts during the first $4 \mathrm{~h}$ of observation (Figure $5 \mathrm{~d}$; $p$ 's $<0.05$ for PVN and VMN, respectively; Bonferroni corrected $t$-tests). Intra-PVN Ucn $3(0.5 \mu \mathrm{g} / \mathrm{side})$ also significantly increased the variability in the rate of eating within bouts as reflected by an increased SD of inter-feeding intervals $(0.0 \mu \mathrm{g}: 0.63 \pm 0.14 ; \quad 0.1 \mu \mathrm{g}: 0.63 \pm 0.23 ; \quad 0.5 \mu \mathrm{g}$ : $0.99 \pm 0.36 \mathrm{mg} / \mathrm{s} ; \quad p=0.02)$. Return map analysis of within-bout inter-feeding intervals ('clustered IFIs', $<35 \mathrm{~s}$ ) further showed that intra-PVN Ucn $3(0.1$ or $0.5 \mu \mathrm{g})$ increased the irregularity of feeding, as reflected in a greater diffuseness of the within-bout spread of Figure $7 \mathrm{~b}$, $c$, e, and $f$ compared to vehicle (Figure $7 \mathrm{a}$ and $\mathrm{d}$ ). The diffuseness of the return map was quantified as the entropy, and intra-PVN Ucn 3 was found to significantly increase the entropy of feeding (Figure $5 \mathrm{e}, p<0.05$, for 0.1 and $0.5 \mu \mathrm{g}$, respectively). Thus, rats treated with intra-PVN Ucn 3 did not maintain high, consistent rates of eating from pellet to pellet (Figure 7a and d), an effect that contributed to their slower overall rate of eating within meals (see Table 3). In contrast, neither intra-VMN nor intra-MeA infusion of Ucn 3 reliably altered the variability of the inter-feeding intervals (SD of IFIs, data not shown) or the entropy (Figure 6e) of eating within bouts. Furthermore, intra-PVN infusion did not alter the variability or serial regularity of the rate of drinking within bouts, indicating a behaviorally specific effect on feeding (data not shown). Ucn 3 did not significantly alter the duration of feeding bouts or the intervals between them following administration into any brain site.

Aspects of bout microstructure other than feeding rate also were affected by intra-hypothalamic Ucn 3 infusion. Intra-VMH Ucn 3 reduced the average size of feeding bouts (Bonferroni corrected $t$-test $p<0.02$, Figure $6 \mathrm{c}$ ), and intraPVN Ucn $3(0.1 \mu \mathrm{g})$ also markedly reduced the number of drinking bouts $(0.0 \mu \mathrm{g}: 6.2 \pm 0.7$ vs $0.1 \mu \mathrm{g}: 2.2 \pm 0.7$ bouts; Bonferroni corrected $t$-test $p<0.0002)$. Intra-hypothalamic 

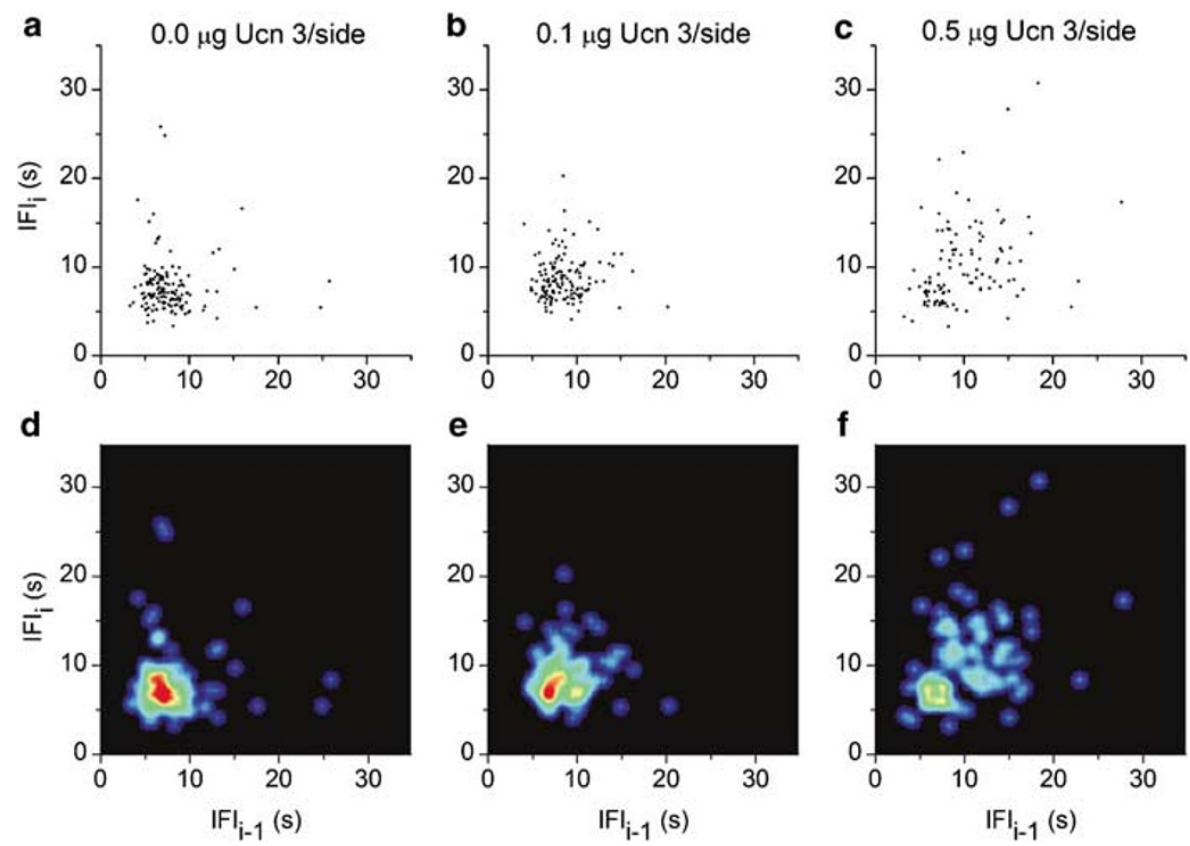

Figure 7 Illustration of the serial regularity within feeding bouts after bilateral injection of murine Ucn 3 into the paraventricular nucleus of the hypothalamus. Panels reflect doses of 0.0 (a, d), 0.1 (b, e), or $0.5 \mu \mathrm{g}$ murine Ucn 3/side (c, f). Return maps (panels a-c) are constructed from 'within-bout' inter-feeding intervals (IFls) from one representative rat (\# PVN-I) during the first 4 post-injection hours. Under vehicle treatment, rats showed serial regularity from pellet to pellet reflected in a 'clustered' return map. Ucn 3 increased the dispersion/irregularity of successive feeding events, reflected as an increased spread and quantified as an increased return map entropy. Panels (d), (e), and (f) show density plots of the IFI return maps (joint IFI probability distribution) in a color-coded form from the representative rat (\# PVN-I). The spreading and decreased 'peakedness' of the pattern indicates the irregularity of feeding within bouts that resulted from Ucn 3 treatment. Warmer colors (toward red) indicate higher local probabilities.

Ucn 3 did not influence other microstructure aspects of drinking bouts.

\section{DISCUSSION}

The present study indicates that Ucn 3 potently reduces nocturnal food intake via a satiety-like mechanism through $\mathrm{CRF}_{2}$-mediated actions in the hypothalamus. Central infusion of Ucn 3 reduced ingestion at doses that did not elicit malaise and which were blocked by cotreatment with a $\mathrm{CRF}_{2}$ receptor antagonist. Forebrain Ucn 3 infusion more potently reduced intake than hindbrain or systemic infusion. LV and intra-hypothalamic Ucn 3 infusion reduced ingestion in nondeprived rats with delayed onset. During anorexia, LV Ucn 3 infusion reduced meal frequency (minimum effective total dose, $0.2 \mu \mathrm{g}$ ) and less potently meal size $(5 \mu \mathrm{g})$. Before the onset of anorexia, Ucn 3 also slowed the eating rate. The hypothalamus was a potent site of Ucn 3 anorexia and also reproduced several aspects of meal microstructure that were altered by LV infusion. Both intra-PVN and intra-VMN infusion reduced meal frequency, prolonged post-meal intervals and slowed the rate of eating within feeding bouts during the period of anorexia. Intra-VMN infusion also reduced the size of feeding bouts, and intra-PVN infusion decreased the regularity of feeding from pellet-to-pellet. Infusions of Ucn 3 that missed hypothalamic target sites were ineffective or less potent than infusions into the VMN or PVN at reducing food intake, meal frequency, and eating rate.
The observed hypothalamic site of anorectic action for Ucn 3 is supported by neuroanatomical studies, which have observed high levels of $\mathrm{CRF}_{2}$ receptor synthesis and binding in the rat hypothalamus (Van Pett et al, 2000; Heinrichs et al, 2001). The dorsomedial VMN is rich with $\mathrm{CRF}_{2}$ receptors (Van Pett et al, 2000) and Ucn 3 terminals (Li et al, 2003), and medial parvocellular (Chalmers et al, 1995) or magnocellular PVN neurons (Van Pett et al, 2000) also reportedly express moderate $\mathrm{CRF}_{2} \mathrm{mRNA}$ levels. Single-unit recording studies of hypothalamic slices found that stresscopin-related peptide, structurally related to Ucn 2, alters firing rates of neurons in the VMN and PVN, supporting their functional sensitivity to $\mathrm{CRF}_{2}$ stimulation (Davidowa and Plagemann, 2004). Infusions of Ucn 3 into these nuclei in the current study, but not into surrounding structures, reduced food intake at a dose of $\sim 20 \mathrm{pmol} /$ side.

The VMN historically was viewed as a 'satiety' center in the dual-center model of feeding because electrical stimulation of the VMN reduced feeding, and lesions resulted in hyperphagia and obesity (Stellar, 1954). Although this simplistic view of the VMN fell into disfavor (Teitelbaum, 1957; Peters et al, 1978), the VMN has been rediscovered as a receptive site for short- and long-term energy feedback signals and forms an integrated component of energy balance neurocircuitry (Zaborszky and Makara, 1979; Luiten and Room, 1980; Ter Horst and Luiten, 1987). Rats with impaired VMN development secondary to deficiency of steroidogenic factor-1, a specific marker of VMN neurons (Segal et al, 2005), are hyperphagic, less active and develop adult-onset obesity (Majdic et al, 2002). The dorsomedial VMN, where injections in the present study were targeted, is 
rich with leptin receptors and glucose-responsive elements analogous to those of pancreatic beta cells (Yang et al, 1999; Miki et al, 2001; Evans et al, 2004; McCrimmon et al, 2004; Squires et al, 2005). Accordingly, the VMN mediates counter-regulatory responses to hypoglycemia and energy balance responses to leptin (Jacob et al, 1997; Satoh et al, 1997; Choi et al, 1999; Dube et al, 1999; Elias et al, 2000; Borg et al, 2003). VMN $\mathrm{CRF}_{2}$ mRNA levels are upregulated by leptin, and pancreatic beta-cell $U \mathrm{cn} 3-\mathrm{CRF}_{2}$ signaling is responsive to extracellular glucose levels (Li et al, 2003), suggesting a homeostatic role for Ucn 3 in responses to short- and long-term fuel availability. Consistent with this view, Zucker $f a / f a$ rats, food-deprived adult rats (Timofeeva and Richard, 1997) and infant rats separated from their dams (Eghbal-Ahmadi et al, 1997), all conditions of perceived energy insufficiency, show decreased VMN $\mathrm{CRF}_{2}$ mRNA levels. Thus, signals of adiposity (e.g., leptin; Hashimoto et al, 2004) or energy availability (e.g., extracellular glucose levels, suckling, maternal sensory cues; Eghbal-Ahmadi et al, 1999) might increase the sensitivity of the VMN to anorectic $\mathrm{CRF}_{2}$ agonists by upregulating $\mathrm{CRF}_{2}$ receptor expression.

Lesions of the PVN also produce obesity and hyperphagia (Tokunaga et al, 1986), and leptin-, ghrelin-, and insulinresponsive arcuate nucleus neurons that express neuropeptide/AgRP and POMC project to the PVN (Horvath, 2005). Like VMN infusion, intra-PVN Ucn 3 produced delayed anorexia by prolonging the post-meal interval. Intra-PVN Ucn 3-treated rats also did not maintain regular, highsustained feeding levels from pellet-to-pellet, a novel aspect of feeding microstructure. Prior studies found that intraPVN Ucn 1 dose-dependently decreased food intake (Currie et $a l, 2001)$ and reduced neuropeptide-induced feeding (Wang et al, 2001a). The current study newly provides evidence that $\mathrm{CRF}_{2}$ receptors are involved in these effects, because Ucn 3, which lacks the $C_{R F}$ affinity of Ucn 1, reduced feeding.

The delayed onset of intra-hypothalamic Ucn 3 anorexia is consistent with that observed after i.c.v. administration of type 2 urocortins in rats (present study; Introduction). Similarly, intracranial CRF receptor agonists exert delayedonset anorexia in $\mathrm{CRF}_{1}$-null mutant mice and fail to produce late-phase anorexia in $\mathrm{CRF}_{2}$ knockouts (see Zorrilla et al, 2003). The results collectively suggest a delayed time course of $\mathrm{CRF}_{2}$ anorexia. Somewhat underappreciated, acute i.c.v. leptin-induced anorexia also is delayed by several hours (see Zorrilla et al, 2005b). Interestingly, leptin appears to be both upstream and downstream of hypothalamic $\mathrm{CRF}_{2}$ action, perhaps providing a physiological context for the current findings. Leptin has receptors on CRFergic hypothalamic neurons (Hakansson et al, 1998), provokes secretion of CRF receptor agonists from hypothalamic explants (Costa et al, 1997; Raber et al, 1997), and stimulates PVN CRF (Schwartz et al, 1996) and $\mathrm{VMH} \mathrm{CRF}_{2}$ mRNA synthesis (Hashimoto et al, 2004). Conversely, Zucker obese $(f a / f a)$ rats, which lack a fully functional leptin receptor, have reduced $\mathrm{VMH} \mathrm{CRF}_{2}$ mRNA expression (Richard et al, 1996). CRF receptor antagonists attenuate leptin-induced Fos-like immunoreactivity in the PVN and VMH (Masaki et al, 2003) as well as leptin-induced anorexia (Gardner et al, 1998). Intra-PVN CRF administration, in turn, increases plasma leptin levels
(Kotz et al, 2002). Intriguingly, LV leptin infusion shares not only the time course but also the microstructure mode of action of intra-hypothalamic Ucn 3 infusion. Both molecules produce delayed anorectic effects most potently by reducing meal frequency and prolonging the inter-meal interval, a facilitation of post-meal satiety (Zorrilla et al, 2005b).

Several mechanisms might proximately account for the delayed onset anorexia of these interrelated molecules. These include the time needed for them to remodel hypothalamic circuits (Pinto et al, 2004; Sternson et al, 2005), to transcribe and translate a directly anorectic molecule, or to modulate/interact with accumulating intake-related satiety signals. For example, CRF receptors in the PVN regulate gastrocolonic motility (Monnikes et al, 1993), with brain $\mathrm{CRF}_{2}$ stimulation slowing gastric emptying (Martinez et al, 2004). Thus, Ucn 3's ability to inhibit gastric motility might account for its ability to prolong postmeal intervals with delayed onset. Meals would empty more slowly and less completely, leading to progressive accrual of food in the stomach during the early dark cycle, prolonged gastric distension, and reduced subsequent intake potential (Kaplan et al, 1994; Phillips and Powley, 1996). The slow onset mode of anorectic action makes $\mathrm{CRF}_{2}$ systems (similar to leptin) more likely to participate in long-term, than short-term, control of food intake.

Intra-MeA Ucn 3 influenced how, but not how much, food was eaten, promoting a nibbling pattern of more, but smaller meals. Bilateral lesions of the MeA similarly produce a nibbling, but quantitatively normal, pattern of food intake in male rats (Larue and Le Magnen, 1972). In the present study, the histological results revealed healthy MeA tissue, and unilateral MeA Ucn 3 infusion (0.5 $\mu \mathrm{g})$ also produces a nibbling meal pattern in male rats (ÉM Fekete and EP Zorrilla, unpublished observations). Trends for intra-MeA Ucn 3 to decrease food intake with delayed onset and prolong post-meal intervals also were observed, although these actions were not as potent as intrahypothalamic administration. Further study with larger sample sizes, increased doses, and site of action analysis for amygdala injections would help to further characterize the ingestive actions of $\operatorname{Ucn} 3$ stimulation in the medial amygdala. The feeding-regulatory functions of the $\mathrm{MeA}$ generally and in response to $U c n 3$ specifically may reflect its connection to the VMN via the stria terminalis (Grundmann et al, 2005).

There is evidence that urocortins can act both centrally (Spina et al, 1996) and peripherally (Wang et al, 2001b) to elicit anoretic effects. The current studies highlight a hypothalamic site of action, but urocortins also may reduce feeding at other brain sites, as Ucn 1 previously potently induced anorexia following infusion into the caudal brainstem (Grill et al, 2000) or LS (Wang et al, 2001a). In the current study, doses of Ucn 3 as much as one order higher than the doses that were effective at forebrain sites did not reduce food intake when applied into the fourth ventricle. Therefore, it is unlikely that the anorectic effects of forebrain Ucn 3 infusion involved diffusion to a caudal hindbrain site of action. Still, the present results do support the possibility that a caudal hindbrain site of action for urocortins may exist, as reflected by the anorectic effects of fourth ventricle Ucn 1 infusion observed here and elsewhere 
(Grill et al, 2000; Daniels et al, 2004). The anorectic potency of Ucn 3 is greater, however, following hypothalamic than after fourth ventricle infusion.

Ucn 3 anorexia does not appear to be due to nonspecific effects on feeding, such as malaise, anxiogenic-like effects, or motor impairment. Unlike LiCl, the minimal effective dose for Ucn 3 anorexia (i.c.v. $1 \mu \mathrm{g}$ ) did not promote formation of a CTA, although, similar to Ucn 2 (Inoue et al, 2003), significantly higher doses might. A caveat to this conclusion is that Ucn 3's anorectic effects are delayed, and the formation of a CTA depends on temporal proximity between the conditioned stimulus and the aversive drug state, so it would be useful to evaluate Ucn 3's actions in a time-insensitive measure of malaise. In this vein, the related $\mathrm{CRF}_{2}$ agonist Ucn 2 did not increase kaolin clay intake (pica), an unconditioned measure of visceral illness at doses through $10 \mu \mathrm{g}$ (Zorrilla et al, 2004). Still, it cannot be ruled out that aversive, 'non-visceral' actions of high doses of Ucn 2 (Inoue et al, 2003) that promoted a CTA might be shared by high doses of Ucn 3. Arguing against anxiogenic-like actions, i.c.v. doses of Ucn 3 infused in the current study reportedly do not increase anxiogenic-like behavior, as reflected in the elevated plus maze (Valdez et al, 2003; Venihaki et al, 2004), defensive burying or social interaction tests (Zhao et al, 2004). Similarly, unlike the anxiogenic-like peptide CRF, Ucn 3 reportedly did not increase activity in familiar environments (Valdez et al, 2003; Ohata and Shibasaki, 2004). Finally, Ucn 3 anorexia does not reflect motor impairment because Ucn 3 reduced food intake without influencing the concurrent drinking rate within meals. Our findings support the suggestion that $\mathrm{CRF}_{2}$, unlike $\mathrm{CRF}_{1}$, stimulation may produce anorexia without aversive consequences (Inoue et al, 2003).

Thus, Ucn 3 reduced food and prandial water intake in nondeprived rats through $\mathrm{CRF}_{2}$-mediated actions without producing signs of malaise. Ucn 3 more potently reduced intake after VMN and PVN infusion. The anorexia resulted from a delayed prolonging of the post-meal interval, a time course, and microstructure similar to that of i.c.v. leptin (Zorrilla et al, 2005b) and which may reflect a functional relation between the $o b$ protein and $\mathrm{CRF}_{2}$ systems. IntraPVN Ucn 3 also decreased the local rate and regularity of eating within bouts of feeding. Together, these data define the hypothalamus as an important site for $\mathrm{Ucn} 3-\mathrm{CRF}_{2}$ control of feeding.

\section{ACKNOWLEDGEMENTS}

We thank Robert Lintz for technical contributions, Glenn Valdez for scholarly discussion, Yanina Grant for assistance with the statistical analysis, and Mike Arends for editorial assistance. This is publication number 17719-NP from The Scripps Research Institute. This study is supported by DK64871, DK70118 and DK26741 from the National Institute of Diabetes and Digestive and Kidney Diseases. ÉMF was supported by the Hungarian Eötvös Fellowship.

\section{REFERENCES}

Behan DP, De Souza EB, Lowry PJ, Potter E, Sawchenko P, Vale WW (1995). Corticotropin releasing factor (CRF) binding protein: a novel regulator of CRF and related peptides. Front Neuroendocrinol 16: 362-382.

Borg MA, Tamborlane WV, Shulman GI, Sherwin RS (2003). Local lactate perfusion of the ventromedial hypothalamus suppresses hypoglycemic counterregulation. Diabetes 52: 663-666.

Chalmers DT, Lovenberg TW, De Souza EB (1995). Localization of novel corticotropin-releasing factor receptor (CRF2) mRNA expression to specific subcortical nuclei in rat brain: comparison with CRF1 receptor mRNA expression. J Neurosci 15: 6340-6350.

Choi S, Sparks R, Clay M, Dallman MF (1999). Rats with hypothalamic obesity are insensitive to central leptin injections. Endocrinology 140: 4426-4433.

Costa A, Poma A, Martignoni E, Nappi G, Ur E, Grossman A (1997). Stimulation of corticotrophin-releasing hormone release by the obese (ob) gene product, leptin, from hypothalamic explants. NeuroReport 8: 1131-1134.

Currie PJ, Coscina DV, Bishop C, Coiro CD, Koob GF, Rivier J et al (2001). Hypothalamic paraventricular nucleus injections of urocortin alter food intake and respiratory quotient. Brain Res 916: $222-228$.

Daniels D, Markison S, Grill HJ, Kaplan JM (2004). Central structures necessary and sufficient for ingestive and glycemic responses to Urocortin I administration. J Neurosci 24: 11457-11462.

Davidowa H, Plagemann A (2004). Hypothalamic neurons of postnatally overfed, overweight rats respond differentially to corticotropin-releasing hormones. Neurosci Lett 371: 64-68.

de Groote L, Penalva RG, Flachskamm C, Reul JM, Linthorst AC (2005). Differential monoaminergic, neuroendocrine and behavioural responses after central administration of corticotropinreleasing factor receptor type 1 and type 2 agonists. J Neurochem 94: $45-56$.

Dekhuijzen AJ, Bagust J (1996). Analysis of neural bursting: nonrhythmic and rhythmic activity in isolated spinal cord. J Neurosci Methods 67: 141-147.

Dube MG, Xu B, Kalra PS, Sninsky CA, Kalra SP (1999). Disruption in neuropeptide $\mathrm{Y}$ and leptin signaling in obese ventromedial hypothalamic-lesioned rats. Brain Res 816: 38-46.

Eghbal-Ahmadi M, Avishai-Eliner S, Hatalski CG, Baram TZ (1999). Differential regulation of the expression of corticotropinreleasing factor receptor type 2 (CRF2) in hypothalamus and amygdala of the immature rat by sensory input and food intake. J Neurosci 19: 3982-3991.

Eghbal-Ahmadi M, Hatalski CG, Avishai-Eliner S, Baram TZ (1997). Corticotropin releasing factor receptor type II (CRF2) messenger ribonucleic acid levels in the hypothalamic ventromedial nucleus of the infant rat are reduced by maternal deprivation. Endocrinology 138: 5048-5051.

Elias CF, Kelly JF, Lee CE, Ahima RS, Drucker DJ, Saper CB et al (2000). Chemical characterization of leptin-activated neurons in the rat brain. J Comp Neurol 423: 261-281.

Evans ML, McCrimmon RJ, Flanagan DE, Keshavarz T, Fan X, McNay EC et al (2004). Hypothalamic ATP-sensitive K+ channels play a key role in sensing hypoglycemia and triggering counterregulatory epinephrine and glucagon responses. Diabetes 53: 2542-2551.

Fekete É, Vígh J, Bagi ÉE, Lénárd L (2002). Gastrin releasing peptide microinjected into the amygdala inhibits feeding. Brain Res 955: 55-63.

Gardner JD, Rothwell NJ, Luheshi GN (1998). Leptin affects food intake via CRF-receptor-mediated pathways. Nat Neurosci 1: 103. Geary N (2005). A new way of looking at eating. Am J Physiol Regul Integr Comp Physiol 288: R1444-R1446.

Grill HJ, Markison S, Ginsberg A, Kaplan JM (2000). Longterm effects on feeding and body weight after stimulation of forebrain or hindbrain CRH receptors with urocortin. Brain Res 867: 19-28. 
Grill HJ, Schwartz MW, Kaplan JM, Foxhall JS, Breininger J, Baskin DG (2002). Evidence that the caudal brainstem is a target for the inhibitory effect of leptin on food intake. Endocrinology 143: 239-246.

Grundmann SJ, Pankey EA, Cook MM, Wood AL, Rollins BL, King BM (2005). Combination unilateral amygdaloid and ventromedial hypothalamic lesions: evidence for a feeding pathway. $A m \mathrm{~J}$ Physiol Regul Integr Comp Physiol 288: R702-R707.

Hakansson ML, Brown H, Ghilardi N, Skoda RC, Meister B (1998). Leptin receptor immunoreactivity in chemically defined target neurons of the hypothalamus. J Neurosci 18: 559-572.

Hashimoto K, Nishiyama M, Tanaka Y, Noguchi T, Asaba K, Hossein PN et al (2004). Urocortins and corticotropin releasing factor type 2 receptors in the hypothalamus and the cardiovascular system. Peptides 25: 1711-1721.

Heinrichs SC, Joppa M, Lapsansky J, Jeske K, Nelson R, De Souza E (2001). Selective stimulatory actions of corticotropin-releasing factor ligands on correlates of energy balance. Physiol Behav 74: $5-13$.

Hoare SR, Sullivan SK, Fan J, Khongsaly K, Grigoriadis DE (2005). Peptide ligand binding properties of the corticotropin-releasing factor (CRF) type 2 receptor: pharmacology of endogenously expressed receptors, G-protein-coupling sensitivity and determinants of CRF(2) receptor selectivity. Peptides 26: 457-470.

Horvath TL (2005). The hardship of obesity: a soft-wired hypothalamus. Nat Neurosci 8: 561-565.

Hsu SY, Hsueh AJ (2001). Human stresscopin and stresscopinrelated peptide are selective ligands for the type 2 corticotropinreleasing hormone receptor. Nat Med 7: 605-611.

Inoue K, Valdez GR, Reyes TM, Reinhardt LE, Tabarin A, Rivier J et al (2003). Human urocortin II, a selective agonist for the type 2 corticotropin-releasing factor receptor, decreases feeding and drinking in the rat. J Pharmacol Exp Ther 305: 385-393.

Jacob RJ, Dziura J, Medwick MB, Leone P, Caprio S, During M et al (1997). The effect of leptin is enhanced by microinjection into the ventromedial hypothalamus. Diabetes 46: 150-152.

Jahn O, Tezval H, van Werven L, Eckart K, Spiess J (2004). Threeamino acid motifs of urocortin II and III determine their CRF receptor subtype selectivity. Neuropharmacology 47: 233-242.

Kaplan JM, Seeley RJ, Grill HJ (1994). A behavioral probe of the growth of intake potential during the inter-meal interval in the rat. Behav Neurosci 108: 353-361.

Kissileff HR (2000). Ingestive behavior microstructure, basic mechanisms and clinical applications. Neurosci Biobehav Rev 24: $171-172$.

Kleiber M, Rogers TA (1961). Energy metabolism. Annu Rev Physiol 23: 5-36.

Kotz CM, Wang C, Levine AS, Billington CJ (2002). Urocortin in the hypothalamic PVN increases leptin and affects uncoupling proteins- 1 and -3 in rats. Am J Physiol Regul Integr Comp Physiol 282: R546-R551.

Larue CG, Le Magnen J (1972). The olfactory control of meal pattern in rats. Physiol Behav 9: 817-821.

Lewis K, Li C, Perrin MH, Blount A, Kunitake K, Donaldson C et al (2001). Identification of urocortin III, an additional member of the corticotropin-releasing factor (CRF) family with high affinity for the CRF2 receptor. Proc Natl Acad Sci USA 98: 7570-7575.

Li C, Chen P, Vaughan J, Blount A, Chen A, Jamieson PM et al (2003). Urocortin III is expressed in pancreatic beta-cells and stimulates insulin and glucagon secretion. Endocrinology 144: 3216-3224.

Li C, Vaughan J, Sawchenko PE, Vale WW (2002). Urocortin IIIimmunoreactive projections in rat brain: partial overlap with sites of type 2 corticotrophin-releasing factor receptor expression. J Neurosci 22: 991-1001.

Li JS, Huston JP (2002). Non-linear dynamics of operant behavior: a new approach via the extended return map. Rev Neurosci 13: $31-57$.
Luiten PG, Room P (1980). Interrelations between lateral, dorsomedial and ventromedial hypothalamic nuclei in the rat. An HRP study. Brain Res 190: 321-332.

Majdic G, Young M, Gomez-Sanchez E, Anderson P, Szczepaniak LS, Dobbins RL et al (2002). Knockout mice lacking steroidogenic factor 1 are a novel genetic model of hypothalamic obesity. Endocrinology 143: 607-614.

Maness LM, Kastin AJ, Farrell CL, Banks WA (1998). Fate of leptin after intracerebroventricular injection into the mouse brain. Endocrinology 139: 4556-4562.

Martinez V, Wang L, Rivier J, Grigoriadis D, Tache Y (2004). Central CRF, urocortins and stress increase colonic transit via CRF1 receptors while activation of CRF2 receptors delays gastric transit in mice. J Physiol 556: 221-234.

Masaki T, Yoshimichi G, Chiba S, Yasuda T, Noguchi H, Kakuma T et al (2003). Corticotropin-releasing hormone-mediated pathway of leptin to regulate feeding, adiposity, and uncoupling protein expression in mice. Endocrinology 144: 3547-3554.

McCrimmon RJ, Fan X, Ding Y, Zhu W, Jacob RJ, Sherwin RS (2004). Potential role for AMP-activated protein kinase in hypoglycemia sensing in the ventromedial hypothalamus. Diabetes 53: 1953-1958.

Miki T, Liss B, Minami K, Shiuchi T, Saraya A, Kashima Y et al (2001). ATP-sensitive $\mathrm{K}+$ channels in the hypothalamus are essential for the maintenance of glucose homeostasis. Nat Neurosci 4: 507-512.

Monnikes H, Schmidt BG, Tache Y (1993). Psychological stress-induced accelerated colonic transit in rats involves hypothalamic corticotropin-releasing factor. Gastroenterology 104: 716-723.

Ohata H, Shibasaki T (2004). Effects of urocortin 2 and 3 on motor activity and food intake in rats. Peptides 25: 1703-1709.

Paxinos G, Watson C (1998). The Rat Brain in Stereotaxic Coordinates. Academic Press: San Diego, CA.

Pellegrino L, Pellegrino A, Cushmann A (1979). A Stereotaxic Atlas of the Rat Brain. Plenum Press: New York, NY.

Pelleymounter MA, Joppa M, Ling N, Foster AC (2004). Behavioral and neuroendocrine effects of the selective CRF2 receptor agonists urocortin II and urocortin III. Peptides 25: 659-666.

Peters R, Luttmers L, Gunion M, Wellman P (1978). Ventromedial hypothalamic syndrome: finickiness? Physiol Behav 20: 279-285.

Phillips RJ, Powley TL (1996). Gastric volume rather than nutrient content inhibits food intake. Am J Physiol 271: R766-R769.

Pinto S, Roseberry AG, Liu H, Diano S, Shanabrough M, Cai X et al (2004). Rapid rewiring of arcuate nucleus feeding circuits by leptin. Science 304: 110-115.

Raber J, Chen S, Mucke L, Feng L (1997). Corticotropin-releasing factor and adrenocorticotrophic hormone as potential central mediators of OB effects. J Biol Chem 272: 15057-15060.

Reyes TM, Lewis K, Perrin MH, Kunitake KS, Vaughan J, Arias CA et al (2001). Urocortin II: a member of the corticotropinreleasing factor (CRF) neuropeptide family that is selectively bound by type 2 CRF receptors. Proc Natl Acad Sci USA 98: 2843-2848.

Richard D, Rivest R, Naimi N, Timofeeva E, Rivest S (1996). Expression of corticotropin-releasing factor and its receptors in the brain of lean and obese Zucker rats. Endocrinology 137: 4786-4795.

Rivier J, Gulyas J, Kirby D, Low W, Perrin MH, Kunitake K et al (2002). Potent and long-acting corticotropin releasing factor (CRF) receptor 2 selective peptide competitive antagonists. J Med Chem 45: 4737-4747.

Satoh N, Ogawa Y, Katsuura G, Tsuji T, Masuzaki H, Hiraoka J et al (1997). Pathophysiological significance of the obese gene product, leptin, in ventromedial hypothalamus (VMH)-lesioned rats: evidence for loss of its satiety effect in VMH-lesioned rats. Endocrinology 138: 947-954. 
Schwartz MW, Seeley RJ, Campfield LA, Burn P, Baskin DG (1996). Identification of targets of leptin action in rat hypothalamus. $J$ Clin Invest 98: 1101-1106.

Seeley RJ, Blake K, Rushing PA, Benoit S, Eng J, Woods SC et al (2000). The role of CNS glucagon-like peptide-1 (7-36) amide receptors in mediating the visceral illness effects of lithium chloride. J Neurosci 20: 1616-1621.

Segal JP, Stallings NR, Lee CE, Zhao L, Socci N, Viale A et al (2005). Use of laser-capture microdissection for the identification of marker genes for the ventromedial hypothalamic nucleus. J Neurosci 25: 4181-4188.

Spina M, Merlo-Pich E, Chan RK, Basso AM, Rivier J, Vale W et al (1996). Appetite-suppressing effects of urocortin, a CRF-related neuropeptide. Science 273: 1561-1564.

Spina MG, Merlo-Pich E, Akwa Y, Balducci C, Basso AM, Zorrilla EP et al (2002). Time-dependent induction of anxiogenic-like effects after central infusion of urocortin or corticotropin-releasing factor in the rat. Psychopharmacology 160: 113-121.

Squires PE, Churamani D, Pararajasingam R, Persaud SJ, Jones PM (2005). Similarities of K+ATP channel expression and $\mathrm{Ca}^{2+}$ changes in pancreatic beta cells and hypothalamic neurons. Pancreas 30: 227-232.

Stellar E (1954). The physiology of motivation. Psychol Rev 61: $5-22$.

Sternson SM, Shepherd GM, Friedman JM (2005). Topographic mapping of $\mathrm{VMH} \rightarrow$ arcuate nucleus microcircuits and their reorganization by fasting. Nat Neurosci 8: 1356-1363.

Szücs A, Pinto RD, Rabinovich MI, Abarbanel HD, Selverston AI (2003). Synaptic modulation of the interspike interval signatures of bursting pyloric neurons. J Neurophysiol 89: 1363-1377.

Teitelbaum P (1957). Random and food-directed activity in hyperphagic and normal rats. J Comp Physiol Psychol 50: 486-490.

Ter Horst GJ, Luiten PG (1987). Phaseolus vulgaris leucoagglutinin tracing of intrahypothalamic connections of the lateral, ventromedial, dorsomedial and paraventricular hypothalamic nuclei in the rat. Brain Res Bull 18: 191-203.

Timofeeva E, Richard D (1997). Functional activation of CRH neurons and expression of the genes encoding $\mathrm{CRH}$ and its receptors in food-deprived lean $(\mathrm{Fa} /$ ?) and obese (fa/fa) Zucker rats. Neuroendocrinology 66: 327-340.

Tokunaga K, Fukushima M, Kemnitz JW, Bray GA (1986). Comparison of ventromedial and paraventricular lesions in rats that become obese. Am J Physiol 251: R1221-R1227.

Ungless MA, Singh V, Crowder TL, Yaka R, Ron D, Bonci A (2003). Corticotropin-releasing factor requires CRF binding protein to potentiate NMDA receptors via CRF receptor 2 in dopamine neurons. Neuron 39: 401-407.
Valdez GR, Zorrilla EP, Rivier J, Vale WW, Koob GF (2003). Locomotor suppressive and anxiolytic-like effects of urocortin 3, a highly selective type 2 corticotropin-releasing factor agonist. Brain Res 980: 206-212.

Van Pett K, Viau V, Bittencourt JC, Chan RK, Li HY, Arias C et al (2000). Distribution of mRNAs encoding CRF receptors in brain and pituitary of rat and mouse. J Comp Neurol 428: 191-212.

Venihaki M, Sakihara S, Subramanian S, Dikkes P, Weninger SC, Liapakis G et al (2004). Urocortin III, a brain neuropeptide of the corticotropin-releasing hormone family: modulation by stress and attenuation of some anxiety-like behaviours. J Neuroendocrinol 16: 411-422.

Wang C, Mullet MA, Glass MJ, Billington CJ, Levine AS, Kotz CM (2001a). Feeding inhibition by urocortin in the rat hypothalamic paraventricular nucleus. Am J Physiol Regul Integr Comp Physiol 280: R473-R480.

Wang L, Martinez V, Rivier JE, Tache Y (2001b). Peripheral urocortin inhibits gastric emptying and food intake in mice: differential role of CRF receptor 2. Am J Physiol Regul Integr Comp Physiol 281: R1401-R1410.

Yang XJ, Kow LM, Funabashi T, Mobbs CV (1999). Hypothalamic glucose sensor: similarities to and differences from pancreatic beta-cell mechanisms. Diabetes 48: 1763-1772.

Zaborszky L, Makara GB (1979). Intrahypothalamic connections: an electron microscopic study in the rat. Exp Brain Res 34: 201-215.

Zhao Y, Fekete E, Brennan M, Mattock M, Rivier J, Vale WW et al (2004). Intracerebroventricular Urocortin 3 lacks the anxietylike properties of corticotropin-releasing factor 1 receptor agonists in rats. In: Society for Neuroscience Abstracts, 30: 1027.14.

Zorrilla EP, Inoue K, Fekete EM, Tabarin A, Valdez GR, Koob GF (2005a). Measuring meals: structure of prandial food and water intake of rats. Am J Physiol Regul Integr Comp Physiol 288: R1450-R1467.

Zorrilla EP, Inoue K, Valdez GR, Tabarin A, Koob GF (2005b). Leptin and post-prandial satiety: acute central leptin more potently reduces meal frequency than meal size in the rat. Psychopharmacology (Berlin) 177: 324-335.

Zorrilla EP, Reinhardt LE, Valdez GR, Inoue K, Rivier JE, Vale WW et al (2004). Human urocortin 2, a corticotropin-releasing factor $\mathrm{CRF}_{2}$ agonist, and ovine CRF, a $\mathrm{CRF}_{1}$ agonist, differentially alter feeding and motor activity. J Pharmacol Exp Ther 310: 1027-1034.

Zorrilla EP, Tache Y, Koob GF (2003). Nibbling at CRF receptor control of feeding and gastrocolonic motility. Trends Pharmacol Sci 24: 421-427. 